\title{
Therapeutic Targeting of TGF Ligands in Glioblastoma Using Novel Antisense Oligonucleotides Reduces the Growth of Experimental Gliomas
}

\author{
Papachristodoulou, Alexandros ; Silginer, Manuela ; Weller, Michael ; Schneider, Hannah ; Hasenbach,
} Kathy ; Janicot, Michel ; Roth, Patrick

\begin{abstract}
PURPOSE Transforming growth factor (TGF)- is expressed at high levels by glioma cells and contributes to the malignant phenotype of glioblastoma. However, its therapeutic targeting remains challenging. Here, we examined an alternative therapeutic approach of TGF inhibition using two novel phosphorothioate-locked nucleic acid (LNA)-modified antisense oligonucleotide gapmers, ISTH1047 and ISTH0047, which specifically target TGF and TGF . EXPERIMENTAL DESIGN We characterized the effects of ISTH1047 and ISTH0047 on TGF expression, downstream signaling and growth of human LN308, LN-229, and ZH-161 cells as well as murine SMA-560 glioma cells . Furthermore, we assessed their target inhibition and effects on survival in orthotopic xenogeneic and syngeneic rodent glioma models . RESULTS Both antisense oligonucleotides specifically silenced their corresponding target and abrogated SMAD2 phosphorylation in several glioma cell lines. Moreover, inhibition of TGF or TGF expression by ISTH1047 or ISTH0047 reduced the migration and invasiveness of LN-308 and SMA-560 glioma cells. Systemic antisense oligonucleotide administration to glioma-bearing mice suppressed or mRNA expression as well as the expression of the downstream target in orthotopic gliomas. Glioma-bearing mice had significantly prolonged survival upon systemic treatment with ISTH1047 or ISTH0047, which was associated with a reduction of intratumoral SMAD2 phosphorylation and, in a fully immunocompetent model, with increased immune cell infiltration. CONCLUSIONS Targeting TGF expression with the novel LNA antisense oligonucleotides ISTH1047 or ISTH0047 results in strong antiglioma activity and , which may represent a promising approach to be examined in human patients with glioma.
\end{abstract}

DOI: https://doi.org/10.1158/1078-0432.CCR-17-3024

Posted at the Zurich Open Repository and Archive, University of Zurich

ZORA URL: https://doi.org/10.5167/uzh-176279

Journal Article

Accepted Version

Originally published at:

Papachristodoulou, Alexandros; Silginer, Manuela; Weller, Michael; Schneider, Hannah; Hasenbach, Kathy; Janicot, Michel; Roth, Patrick (2019). Therapeutic Targeting of TGF Ligands in Glioblastoma Using Novel Antisense Oligonucleotides Reduces the Growth of Experimental Gliomas. Clinical Cancer Research, 25(23):7189-7201.

DOI: https://doi.org/10.1158/1078-0432.CCR-17-3024 
1 Therapeutic targeting of TGF- $\beta$ ligands in glioblastoma using novel antisense

2 oligonucleotides reduces the growth of experimental gliomas

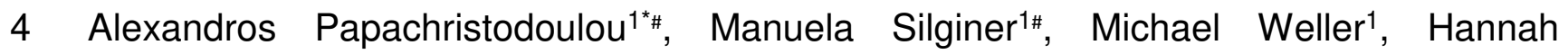

5 Schneider ${ }^{1}$, Kathy Hasenbach ${ }^{2}$, Michel Janicot ${ }^{2}$, Patrick Roth ${ }^{1}$

$6{ }^{1}$ Laboratory of Molecular Neuro-Oncology, Department of Neurology, University Hospital

7 Zurich and University of Zurich, Switzerland; ${ }^{2}$ Isarna Therapeutics $\mathrm{GmbH}$, Munich,

8 Germany; *Present address: Departments of Urology and Pathology and Cell Biology,

9 Herbert Irving Comprehensive Cancer Center, Columbia University, 1139 St. Nicholas

10 Avenue, 10032 New York, USA

11 \# These authors contributed equally.

13 Corresponding author: Patrick Roth, MD, Department of Neurology, University Hospital

14 Zurich and University of Zurich, Frauenklinikstrasse 26, 8091 Zurich, Switzerland, Phone:

15 +41 (0)44 2555511, Fax: +41- (0)44 255 4380, E-mail: patrick.roth@usz.ch

17 Conflict of interest: PR has received honoraria for advisory boards and lectures from

18 BMS, Roche, MSD, Novartis, Novocure, Covagen, Virometix and Molecular Partners. MW

19 has received research grants from Abbvie, Adastra, Bayer, Isarna, Merck, Sharp \&

20 Dohme (MSD), EMD Pharmaceuticals, Piqur and Roche and honoraria for lectures or

21 advisory board participation from Abbvie, Celgene, MSD, EMD Pharmaceuticals, Pfizer,

22 Roche and Teva. KH and MJ are employees of Isarna. AP, MS and HS have nothing to 23 disclose. 
25 Running title: Anti-glioma effect of antisense-mediated TGF- $\beta$ inhibition

26 Keywords: Glioblastoma, TGF- $\beta_{1}$, TGF- $\beta_{2}$, antisense oligonucleotide, pSMAD2

\section{Statement of translational relevance}

29 Transforming growth factor (TGF)- $\beta$ has been attributed an important role in glioblastoma

30 progression and may be a key player in tumor invasion, angiogenesis and

31 immunosuppression. Targeting the TGF- $\beta$ pathway has been regarded a promising

32 therapeutic strategic but the approaches used to date have failed due to insufficient

33 inhibition of the TGF- $\beta$ pathway or dose-limiting toxicity. In this study, we directly inhibited

34 TGF- $\beta_{1}$ or TGF- $\beta_{2}$ expression with novel second-generation antisense oligonucleotides

35 (ASO). We demonstrate that ASO-mediated TGF- $\beta$ inhibition reduces the invasive

36 potential of glioma cells, while increasing the number of tumor-infiltrating immune cells.

37 These novel TGF- $\beta$-targeting ASO reach the tumor upon systemic administration and

38 prolong survival of both immunocompetent and immune-deficient mice bearing orthotopic

39 gliomas. Therefore, this study represents a major improvement in TGF- $\beta$-targeted

40 therapy, with high promise for clinical translation in human glioma patients. 


\section{Abstract}

49 Purpose: Transforming growth factor (TGF)- $\beta$ is expressed at high levels by glioma cells 50 and contributes to the malignant phenotype of glioblastoma. However, its therapeutic 51 targeting remains challenging. Here, we examined an alternative therapeutic approach of 52 TGF- $\beta$ inhibition using two novel phosphorothioate-locked nucleic acid (LNA)-modified 53 antisense oligonucleotide gapmers, ISTH1047 and ISTH0047, which specifically target 54 TGF- $\beta_{1}$ and TGF- $\beta_{2}$.

55 Experimental design: We characterized the effects of ISTH1047 and ISTH0047 on TGF-

$56 \beta_{1 / 2}$ expression, downstream signaling and growth of human $\mathrm{LN}-308, \mathrm{LN}-229$ and $\mathrm{ZH}-161$

57 cells as well as murine SMA-560 glioma cells in vitro. Furthermore, we assessed their

58 target inhibition and effects on survival in orthotopic xenogeneic and syngeneic rodent 59 glioma models in vivo.

60 Results: Both antisense oligonucleotides specifically silenced their corresponding target

61 and abrogated SMAD2 phosphorylation in several glioma cell lines. Moreover, inhibition 62 of TGF- $\beta_{1}$ or TGF- $\beta_{2}$ expression by ISTH1047 or ISTH0047 reduced migration and 63 invasiveness of LN-308 and SMA-560 glioma cells. Systemic ASO administration to 64 glioma-bearing mice suppressed $T G F-\beta_{1}$ or $T G F-\beta_{2}$ mRNA expression as well as the 65 expression of the down-stream target $P A l-1$ in orthotopic gliomas. Glioma-bearing mice 66 had significantly prolonged survival upon systemic treatment with ISTH1047 or 67 ISTH0047, which was associated with a reduction of intratumoral SMAD2 68 phosphorylation and, in a fully immunocompetent model, with increased immune cell 69 infiltration. 
70 Conclusions: Targeting TGF- $\beta$ expression with the novel LNA antisense

71 oligonucleotides ISTH1047 or ISTH0047 results in strong anti-glioma activity in vitro and

72 in vivo which may represent a promising approach to be examined in human glioma

73 patients.

74

75

76

77

78

79

80

81

82

83

84

85

86

87

88

89

90

91

92 


\section{Introduction}

94 Glioblastoma is the most lethal primary tumor of the central nervous system (CNS) in

95 adults. The current standard of care for newly diagnosed glioblastoma includes surgical

96 resection followed by radiotherapy and chemotherapy with the alkylating agent,

97 temozolomide (TMZ). However, the median survival of glioblastoma patients is still limited

98 to approximately 16 months with a 5 -year survival rate of less than $10 \%$ within clinical

99 trials (1). A key mediator of the malignant phenotype of glioma cells is transforming growth

100 factor (TGF)- $\beta$. It has pleiotropic functions and exists as three different mature ligands,

101 TGF- $\beta_{1}$, TGF- $\beta_{2}$ and TGF- $\beta_{3}$ (2). All are involved in the phosphorylation of SMAD2 and

102 SMAD3 proteins which are responsible for transcriptional regulation of genes involved in

103 tumor infiltration and epithelial to mesenchymal transition (EMT), but also

104 immunosuppression and angiogenesis $(3,4)$. Elevated levels of TGF- $\beta$ as well as the

105 activation of the TGF- $\beta /$ SMAD cascade correlates with high tumor grade and in some

106 cases with poor prognosis in glioblastoma patients $(5,6)$. Gliomas generate an

107 immunosuppressive tumor microenvironment through the secretion of a variety of

108 cytokines, including TGF- $\beta$ that can impede anti-tumor immune responses (3).

109 Furthermore, TGF- $\beta$ signaling enhances the invasiveness and migratory ability of glioma

110 cells and maintains a drug-resistant stem cell phenotype $(7,8)$. Consequently, targeting

111 the TGF- $\beta$ pathway represents an attractive therapeutic approach. In this regard, various

112 strategies have been explored in vitro and in vivo including gene transfer of TGF- $\beta$

113 scavengers such as decorin (9), furin protease inhibitors which interfere with the

114 processing of TGF- $\beta$ (10) or indirect TGF- $\beta$ signaling targeting through integrin inhibition

115 (11). The most advanced approaches comprise TGF- $\beta$ receptor (TGF- $\beta$ R)-1 inhibitors 
116 such as SD-208 (12), galunisertib (13) or LY2109761 (14) and the pan TGF- $\beta$ antibody,

117 1D11 (15). Despite promising pre-clinical data, these agents failed to show a clear clinical

118 benefit in glioblastoma patients $(16,17)$. Therefore, the clinical development of most of

119 these drugs has been stopped because of lack of activity, most likely due to insufficient

120 target inhibition or dose-limiting toxicity (16).

121 Antisense oligonucleotides (ASO) are single-stranded, biochemically-modified

122 deoxyribonucleotide molecules that are 15-25 nucleotides in length. They are designed

123 as complementary sequences to a target gene's mRNA thereby specifically inhibiting

124 gene expression (18). The concept of ASO-mediated gene silencing has emerged as a

125 potentially powerful alternative or concomitant treatment to conventional cancer therapy.

126 There is a plethora of genes related to cancer progression or therapeutic resistance which

127 cannot be targeted efficiently with antibodies or small molecules but possibly with ASO.

128 Because of their targeted mode of action, ASO may be less toxic than many conventional

129 anti-tumor therapeutics (19). One of the most clinically advanced TGF- $\beta$-targeting

130 approaches involved the locoregional application of AP12009 (trabedersen), a first

131 generation ASO with a sequence complementary to human TGF- $\beta_{2}$ mRNA, in a

132 randomized phase II trial in patients with recurrent anaplastic glioma or glioblastoma.

133 Even though AP12009 was not inferior to standard chemotherapy, no convincing efficacy

134 signal was seen (20).

135 Given the insufficient results obtained with the TGF- $\beta$-targeting strategies explored so far,

136 we aimed at assessing TGF- $\beta$ signaling inhibition in glioma models using two novel

137 second-generation phosphorothioate-locked nucleic acid (LNA)-modified ASO. The

138 chemical structure of LNA-modified ASO offers significant advantages such as increased 
139 binding affinity and higher tissue concentrations $(21,22)$. Here, we assessed the anti-

140 glioma activity of two novel LNA-modified ASO molecules which specifically target TGF-

$141 \beta_{1}$ (ISTH1047) or TGF- $\beta_{2}$ (ISTH0047) in several in vitro and in vivo glioma models. 


\section{Materials and methods}

163 Reagents and cell lines

164 The human malignant glioma cell lines LN-308 and LN-229 were kindly provided by Dr.

165 N. de Tribolet (Lausanne, Switzerland). The mouse glioma cell line SMA-560 was derived 166 from a spontaneous astrocytoma in a VM/Dk mouse (23) and provided by Dr. D. Bigner 167 (Durham, NC). The glioma cell lines were maintained in Dulbecco's modified Eagle's 168 medium supplemented with $10 \%$ fetal calf serum (Biochrom, Minneapolis, MN) and 2 $169 \mathrm{mmol} / \mathrm{L}$ L-glutamine (Gibco Life Technologies, Paisley, UK). The glioma-initiating cell 170 (GIC) line $\mathrm{ZH}-161$ was established after informed consent and approval of the Swiss 171 ethical committees and characterized in detail (24). $\mathrm{ZH}-161$ cells were grown in

172 Neurobasal medium supplemented with $2 \mu \mathrm{l} / \mathrm{ml}$ B-27 without vitamin A, $2 \mathrm{mM} \mathrm{L-glutamine}$

173 (Gibco Life Technologies), fibroblast growth factor (FGF)-2 and epidermal growth factor

174 (EGF) (20 ng/mL each, Peprotech, Rocky Hill, PA). All cells were grown in a humidified $17537^{\circ} \mathrm{C}$ incubator with $5 \% \mathrm{CO}_{2}$. ISTH1047, ISTH0047 and C3_ISTH0047 (scrambled 176 control) antisense oligonucleotides were designed and provided by ISARNA Therapeutics

$177 \mathrm{GmbH}$ (Munich, Germany). ISTH1047, targeting TGF- $\beta_{1}$ (sequence 178 TCGATGCGCTTCCG), and ISTH0047, targeting TGF- $\beta_{2}$ (sequence

179 CAAAGTATTTGGTCTCC), represent 14-mer and 17-mer, full locked nucleic acid (LNA)180 modified antisense oligonucleotide gapmers (Suppl. Fig. 1). The specificity of each ASO 181 was confirmed via the NCBI BLAST ${ }^{\circledR}$ software (https://blast.ncbi.nlm.nih.gov/Blast.cgi) to 182 align oligonucleotides to human and murine TGF- $\beta_{1}$ or TGF- $\beta_{2}$ sequences (Suppl. Fig. 2).

183 Digoxigenin (DIG)-labelled ISTH1047 was also provided by ISARNA Therapeutics

$184 \mathrm{GmbH}$. Recombinant human TGF- $\beta_{1 / 2}$ was purchased from R\&D Systems (Minneapolis, 
185 MN). SD-208 was provided by Scios (Fremont, CA) and galunisertib (LY2157299) by Eli

186 Lilly Co (Indianapolis, IN).

187 Real-time quantitative PCR

188 Total RNA was isolated with the NucleoSpin System (Macherey-Nagel, Düren, Germany)

189 and cDNA was retro-transcribed using Invitrogen Superscript II reverse transcriptase

190 (ThermoFisher Scientific, Waltham, MA). For real-time quantitative PCR, cDNA

191 amplification was quantified using SYBR Green chemistry on the 7300 Real time PCR

192 System (Applied Biosystems, Zug, Switzerland). The conditions for the PCR reactions

193 were: 40 cycles, $95^{\circ} \mathrm{C} / 15 \mathrm{sec}, 60^{\circ} \mathrm{C} / 1 \mathrm{~min}$. Human and mouse HPRT1 transcript levels

194 were used as a reference for relative quantification of mRNA expression levels via the

$195 \Delta \mathrm{CT}_{\mathrm{t}}$ method (25). The following specific primers were used: human HPRT1 fwd: 5'-TGA

196 GGA TTT GGA AAG GGT GT-3'; human HPRT1 rev: 5'-GAG CAC ACA GAG GGC TAC

197 AA-3'; human TGF- $\beta_{1}$ fwd: 5'-GCC CTG GAC ACC AAC TAT TG-3'; human TGF- $\beta_{1}$ rev:

198 5'-CGT GTC CAG GCT CCA AAT G-3'; human TGF- $\beta_{2}$ fwd: 5'-AAG CTT ACA CTG TCC

199 CTG CTG C-3'; human TGF- $\beta_{2}$ rev: 5'-TGT GGA GGT GCC ATC AAT ACC T-3'; human

200 TGF- $\beta_{3}$ fwd: 5'-ATG ACC CAC GTC CCC TAT CA-3', human TGF- $\beta_{3}$ rev: 5'-CAG ACA

201 GCC AGT TCG TTG TG-3'; mouse HPRT1 fwd: 5'-TTG CTG ACC TGC TGG ATT AC-

202 3'; mouse HPRT1 rev: 5'-TTT ATG TCC CCC GTT GAC TG-3'; mouse TGF- $\beta_{1}$ fwd: 5'-

203 CTC CCG TGG CTT CTA GTG C-3'; mouse TGF- $\beta_{1}$ rev: 5'-GCC TTA GTT TGG ACA

204 GGA TCT G-3'; mouse TGF- $\beta_{2}$ fwd: 5'-TCG ACA TGG CTT CTA GTG C-3'; mouse TGF-

$205 \beta_{2}$ rev: 5'-CCC TGG TAC TGT TGT AGA TGG A-3'; mouse TGF- $\beta_{3}$ fwd: 5'-

206 AGCATCCACTGTCCATGTCA-3', mouse TGF- $\beta_{3}$ rev: 5'-TTCTTCCTCTGACTGCCCTG-

207 3'; mouse plasminogen activator inhibitor (PAI)-1 fwd: 5'-TCT GGG AAA GGG TTC ACT 
208 TTA CC-3', mouse plasminogen activator inhibitor (PAI)-1 rev: 5'-GAC ACG CCA TAG 209 GGA GAG AAG-3'. For expression analysis of human targets in the oligonucleotide210 treated xenograft mouse model, the following human-specific primers, which do not 211 recognize the mouse TGF- $\beta_{1}$, TGF- $\beta_{2}$ or TGF- $\beta_{3}$ isoforms, were used: TGF- $\beta_{1}$ fwd: $5^{\prime}-$ 212 CAATTCCTGGCGATACCTCAG-3'; TGF- $\beta_{1}$ rev: 5'-GCACAACTCCGGTGACATCAA-3'; 213 TGF- $\beta_{2}$ fwd: 5'-CAGCACACTCGATATGGACCA-3'; TGF- $\beta_{2}$ rev: 5'214 CCTCGGGCTCAGGATAGTCT-3'; TGF- $\beta_{3}$ fwd: 5'-AACGGTGATGACCCACGTC-3', 215 TGF- $\beta_{3}$ rev: 5'-CCGACTCGGTGTTTTCCTGG-3'; PAl1 fwd: $\quad$ 5'216 CAGAAAGTGAAGATCGAGGTGAAC-3'; PAl1 rev: 217 GGAAGGGTCTGTCCATGATGAA-3'.

218

219 Immunoblot

220 Whole protein lysates were generated by lysing the cells with lysis buffer $P$ (26). 221 Denatured whole protein lysates and concentrated supernatants (30 $\mu \mathrm{g} / \mathrm{lane})$ were 222 separated on $10-15 \%$ acrylamide gels. After transfer to nitrocellulose (Biorad, Hercules, $223 \mathrm{CA}$ ), blots were blocked in $5 \%$ milk-TBST and incubated overnight at $4^{\circ} \mathrm{C}$ with primary 224 antibodies specific for: total SMAD2 (clone 86F7, Cell Signaling, Boston, MA) 225 phosphorylated SMAD2 (pSMAD2) (clone 138D4, Cell Signaling), total SMAD3 (Cell 226 Signaling), phosphorylated SMAD3 (pSMAD3) (clone C25A9, Cell Signaling), total AKT 227 (Cell Signaling), phosphorylated AKT (pAKT) (Cell Signaling) and $\beta$-actin (clone sc-1616, 228 Santa Cruz Biotechnologies, Santa Cruz, CA). The membranes were then washed in 229 TBST and incubated for $1 \mathrm{~h}$ at room temperature with horseradish peroxidase (HRP)230 coupled secondary antibodies: anti-rabbit or anti-goat (clones sc-2004 and sc-2033, 
231 Santa Cruz Biotechnologies). Protein bands were visualized by enhanced 232 chemoluminescence (Pierce/Thermo Fisher, Madison, WI).

\section{Animal studies}

235 All procedures were performed in accordance with the Cantonal Veterinary Office Zurich 236 and Federal Food Safety and Veterinary Office. For the xenograft models, Crl: CD1 Foxn1

237 nude mice were purchased from Charles River Laboratories (Wilmington, MA). For the 238 syngeneic studies, VM/Dk mice were bred in house. Mice of 6-10 weeks of age were used 239 in all experiments. Mice were anaesthetized using an intraperitoneal 3 component 240 injection consisting of fentanyl, midazolam and medetomidin (26). For intracranial tumor 241 cell implantation, the mice were fixed under a stereotactic device (Stoelting, Wood Dale, $242 \mathrm{IL}$ ) and a burr hole was drilled in the skull $2 \mathrm{~mm}$ lateral and $1 \mathrm{~mm}$ posterior to the bregma.

243 A Hamilton syringe needle was introduced to a depth of $3 \mathrm{~mm}$. LN-308, LN-229 or ZH244161 human glioma cells $\left(10^{5}\right)$ or SMA-560 murine glioma cells $\left(5 \times 10^{3}\right)$ in a volume of $2 \mu \mathrm{l}$

245 PBS were injected into the right striatum of Crl: CD1 Foxn1 nude or VM/Dk mice, 246 respectively. C3_ISTH0047 (20 mg/kg), ISTH1047 (10 mg/kg) or ISTH0047 (20 mg/kg)

247 were injected subcutaneously for five consecutive days for studies that aimed at 248 assessing target inhibition. Forty-eight hours after the last injection, all mice were PBS249 perfused and organs were harvested for further analyses. For survival studies, C3_ISTH $2500047(20 \mathrm{mg} / \mathrm{kg})$, ISTH1047 (10 mg/kg) or ISTH0047 (20 mg/kg) were injected 251 subcutaneously for five consecutive days and then twice weekly. Mice were monitored 252 daily for neurological symptoms according to Cantonal Veterinary Office Zurich guidelines 253 and euthanized when exhibiting grade 2 symptoms: grade 0 - no visible impairment; 
254 grade 1 - reduced activity, slight imbalance, balance and coordination impairments; grade 2552 - decreased to no activity, $15 \%$ weight loss compared with peak weight measured on 256 tumor inoculation day, slight paralysis of left legs and moderate signs of pain (26).

257 Treatment was started at day 5 after tumor cell inoculation for VM/Dk mice and at day 25 258 (LN-308) or day 10 (LN-229, ZH-161) after tumor cell injection for Crl: CD1 Foxn1 nude 259 animals. For the assessment of oligonucleotide delivery to the brain, digoxigenin (DIG)260 labelled ISTH1047 (10 mg/kg) was subcutaneously injected for two consecutive days and 261 the mice were PBS-perfused $48 \mathrm{~h}$ after the last injection. For liver enzyme analyses, blood 262 was collected from LN-308-bearing mice on the day the first animal became symptomatic 263 and sent for aspartate transaminase (ASAT) and alanine transaminase (ALAT)

264 quantification at the Laboratory for Veterinary Medicine (University of Zurich, 265 Switzerland).

267 Statistical analysis

268 Data were derived from experiments performed at least twice in triplicates with similar 269 results. Quantitative data are presented as mean \pm standard deviation (SD). Statistical 270 significance was assessed using one-way ANOVA using Bonferroni correction as a post271 hoc test. All statistical analyses were performed using Prism 5 (GraphPad Software, La 272 Jolla, CA) at $p<0.05$ or $p<0.01$.

273

274 Additional methods are described in the Supplementary data. 275 
276 Results

277 ISTH1047 and ISTH0047 decrease TGF- $\beta_{1 / 2}$ expression and abrogate TGF- $\beta$ 278 signaling in glioma cells in vitro

279 Based on the chosen sequence, ISTH1047 and ISTH0047 were designed as antisense 280 oligonucleotides specifically inhibiting TGF- $\beta_{1}$ or TGF- $\beta_{2}$ (Suppl Fig. 1,2). First, we 281 examined the biological effects of both oligonucleotides in human LN-308 and mouse 282 SMA-560 glioma cells in vitro. ISTH1047 down-regulated TGF- $\beta 1$ protein levels up to 96 283 h post-transfection in both cell lines, whereas ISTH0047 reduced TGF- $\beta_{2}$ protein levels 284 for up to $96 \mathrm{~h}$ in LN-308 cells and $72 \mathrm{~h}$ in SMA-560 cells (Fig. 1A,B). Increasing 285 concentrations of both oligonucleotides reduced the expression of their corresponding 286 target TGF- $\beta$ ligand at mRNA level, reaching the highest inhibition efficiency at $50 \mathrm{nM}$ or 287 more in both cell lines (Suppl Fig. 3A,B). Moreover, TGF- $\beta_{1}$ or TGF- $\beta_{2}$ mRNA levels were 288 significantly reduced up to $72 \mathrm{~h}$ post-transfection in human $\mathrm{LN}-308, \mathrm{LN}-229$ and $\mathrm{ZH}-161$ 289 glioma cells as well as the murine glioma cell line SMA-560. TGF- $\beta_{3}$ mRNA levels were 290 not significantly affected after ASO transfection in LN-308 or SMA-560 cells, but 291 ISTH0047 exposure increased TGF- $\beta_{3}$ levels in LN-229 cells and reduced TGF- $\beta_{3}$ mRNA 292 levels in $\mathrm{ZH}-161$ cells (Fig. 1C). We observed a reduction of intracellular SMAD2 293 phosphorylation with increasing concentrations of ISTH1047 or ISTH0047 in LN-308 and 294 SMA-560 cells. ISTH1047 diminished pSMAD2 starting at a concentration of $3.13 \mathrm{nM}$ and 295 ISTH0047 at $12.5 \mathrm{nM}$ in LN-308 cells (Suppl Fig. 3C). In SMA-560 cells, ISTH1047 296 abrogated SMAD2 phosphorylation at $50 \mathrm{nM}$, while ISTH0047 exerted strongest effects 297 at $100 \mathrm{nM}$ (Suppl Fig. 3D). Total SMAD2 levels were not altered upon ISTH1047 or 298 ISTH0047 transfection in either cell line (Suppl Fig. 3C,D). The decrease of pSMAD2 
299 levels occurred at $48 \mathrm{~h}$ after transfection (Fig. 1D). Similarly, pSMAD3 levels were 300 reduced in both LN-308 and SMA-560 cells. To assess the effect of TGF- $\beta_{1}$ or TGF- $\beta_{2}$

301 inhibition on alternative TGF- $\beta$ signaling pathways, we examined the phosphorylation 302 levels of AKT $48 \mathrm{~h}$ after ASO exposure. pAKT was reduced following exposure to 303 ISTH1047 or ISTH0047 only in LN-308 cells (Fig. 1E). In line with these findings, exposure 304 to ISTH1047 or ISTH0047 reduced pSMAD2 and pSMAD3 expression in LN-229 cells 305 and the GIC line $\mathrm{ZH}-161$. No consistent effect of ASO-mediated TGF- $\beta$ inhibition on 306 pAKT levels was observed in these cells (Fig. 1F).

307

308 Oligonucleotide-driven TGF- $\beta$ inhibition impairs glioma cell migration and invasion

309 We went on to examine the biological effects of ISTH1047 and ISTH0047 on the viability

310 and clonogenicity of glioma cells. A concentration of $50 \mathrm{nM}$ of either oligonucleotide alone

311 had no impact on cell viability (Suppl. Fig. 4A,B). Moreover, in clonogenic survival assays,

312 transfection with either oligonucleotide had no effect in LN-308 cells although ISTH1047

313 reduced colony formation of SMA-560 cells (Suppl. Fig. 4C,D). Migration and invasion

314 into the surrounding tissue can be induced by TGF- $\beta$ and are among the hallmarks of 315 glioblastoma. Exposure to ISTH1047 reduced migration of LN-308 and SMA-560 cells in 316 Boyden chamber assays. A similar inhibition of glioma cell migration was observed with 317 ISTH0047. Conversely, addition of exogenous TGF- $\beta_{1 / 2}$ resulted in increased glioma cell 318 migration (Fig. 2A,B; Suppl. Fig. 5). To assess whether the two oligonucleotides impair 319 invasiveness of glioma cells, we performed spheroid invasion assays into a three320 dimensional collagen I gel. Spheroid invasion was significantly reduced following TGF$321 \beta_{1}$ - or $-\beta_{2}$-specific oligonucleotide transfection for up to $96 \mathrm{~h}$ in $\mathrm{LN}-308$ cells, while 
322 exogenous TGF- $\beta_{1}$ stimulation increased invasiveness at 96 h (Fig. 2C; Suppl. Fig. 6A).

323 In SMA-560 cells, ISTH1047 transfection blocked spheroid formation in agar. Targeting

324 TGF- $\beta_{2}$ using ISTH0047 led to a significant reduction in spheroid invasion, whereas

325 stimulation with exogenous TGF- $\beta_{2}$ increased the invasion of SMA-560 cells (Fig. 2D;

326 Suppl. Fig. 6B).

327

$328 T$ TGF $\beta_{1 / 2}$ inhibition in murine glioma models in vivo

329 Because of the strong anti-TGF- $\beta$ activity of the two ASO molecules observed in vitro, we

330 aimed at exploring target down-regulation in vivo using the xenogeneic $\mathrm{LN}-308$ as well as

331 the syngeneic SMA-560 model. To this end, we determined whether systemically

332 administered ISTH1047 or ISTH0047 reach the tumor site and inhibit TGF- $\beta_{1}$ or TGF- $\beta_{2}$

333 expression in experimental gliomas. DIG-labelled ISTH1047 was detected specifically in

334 the tumor region upon systemic administration in mice bearing LN-308- or SMA-560-

335 derived gliomas (Fig. 3A-E). Moreover, systemic administration of ISTH1047 or ISTH0047

336 to mice with intracranially growing gliomas resulted in a significant down-regulation of

$337 T G F-\beta_{1}$ or TGF- $\beta_{2}$ mRNA expression levels, respectively, in the tumor-bearing

338 hemisphere without significantly altering $T G F-\beta_{3}$ levels (Fig. 3F). To examine whether the

339 observed target down-regulation had an effect on TGF- $\beta$-dependent downstream

340 signaling, we assessed the expression of PAl1, a classical TGF- $\beta$ response gene (27).

341 Indeed, PA/1 mRNA levels were significantly down-regulated in gliomas derived from LN-

342308 or SMA-560 cells following systemic treatment with ISTH1047 or ISTH0047 (Fig. 3G).

343 Expression levels of all assessed targets were up-regulated in the tumor-bearing

344 hemisphere compared to the normal counterpart, apart from $T G F-\beta_{2}$ and $T G F-\beta_{3}$ levels 
345 in the SMA-560 model.TGF- $\beta_{2}$ levels were also reduced after ISTH0047 treatment in the 346 normal hemisphere in both glioma models (Fig. 3F,G).

347 After confirmation of ASO delivery and target inhibition in experimental gliomas, we

348 assessed effects on survival. Systemic treatment with either ASO prolonged survival of 349 mice with orthotopically growing xenogeneic LN-308- or syngeneic SMA-560-derived 350 gliomas (Fig. 4A,G). Tumor volumes were reduced in mice receiving ISTH1047 or

351 ISTH0047 treatment in both models (Fig. 4B,H). In LN-229-bearing mice, although only 352 ISTH0047 exerted a significant survival benefit, neither treatment reduced the tumor 353 volume at an early time point of analysis (Fig. 4C,D; Suppl. Fig.7). On the contrary, in the $354 \mathrm{ZH}-161$ model, we observed a significantly reduced tumor burden in mice treated with 355 ISTH0047 that exhibited a non-significant trend for better survival compared to control356 treated mice (Fig. 4E,F). Furthermore, treatment with ISTH1047 or ISTH0047 reduced 357 tumoral SMAD2 phosphorylation in LN-308-, LN-229- and SMA-560-bearing mice (Fig. 358 5). The number of invasive glioma satellites was also decreased in gliomas of mice 359 treated with TGF- $\beta$-targeting ASO (Suppl. Fig. 8).

360 For a detailed evaluation of host cell infiltration in the tumor, we assessed the frequencies 361 of different immune cell populations after ISTH1047 or ISTH0047 treatment in the 362 syngeneic, immunocompetent SMA-560 glioma model. We observed a significant 363 increase in the CD45+ leukocyte population in ISTH0047-treated mice, which correlated 364 with an increased infiltration by $\mathrm{CD}^{+} \mathrm{T}$ cells (Fig. 6A,B). Although $\mathrm{CD} 45^{+} / \mathrm{CD}^{+}$cells 365 exhibited an increase by trend only in ISTH1047-treated mice, the cytotoxic CD8 ${ }^{+} \mathrm{T}$ cell 366 population was significantly enriched in the tumors of mice treated with either ISTH1047 367 or ISTH0047 (Fig. 6C). CD4 ${ }^{+}$T cells and CD11 b+ macrophage/microglial cells were not 
368 more frequent in the tumor upon ASO treatment (Fig. 6D,E). In terms of blood vessel 369 density, ISTH0047 reduced the number of CD31+ endothelial cells (Suppl. Fig. 9).

370 Finally, treatment with either oligonucleotide alone was well tolerated without significant

371 weight loss. Blood analyses of mice treated with ISTH1047 demonstrated increased

372 aspartate transaminase (ASAT) and alanine transaminase (ALAT) levels, without any

373 clinically apparent adverse symptoms (Suppl. Fig. 10).

374

375

376

377

378

379

380

381

382

383

384

385

386 


\section{Discussion}

388 TGF- $\beta$ signaling represents a central hub orchestrating various biological functions that 389 are involved in the malignant phenotype of glioblastoma. TGF- $\beta_{1}$ and TGF- $\beta_{2}$ are 390 significantly upregulated compared to normal brain tissue, and the expression of TGF- $\beta_{1}$

391 correlates with the expression of the target gene PAl1 (6). Therefore, a ligand-based 392 approach to directly inhibit TGF- $\beta_{1}$ or TGF- $\beta_{2}$ with ASO represents an attractive 393 therapeutic strategy. The promising but inconclusive results of a trial assessing the local 394 administration of a first generation ASO targeting human TGF- $\beta_{2}$ mRNA (20) led to the 395 development of two second generation LNA-modified ASO, ISTH1047 and ISTH0047 396 targeting TGF- $\beta_{1}$ and TGF- $\beta_{2}$, respectively (Suppl. Fig. 1) that can be administered 397 systemically. ISTH1047 and ISTH0047 are second-generation ASO that benefit from the 398 addition of LNA modifications, which increase their RNA binding affinity and confer 399 enhanced nuclease resistance versus first-generation molecules (28). Here, we 400 characterized the anti-glioma activity of these novel ASO in human and mouse glioma 401 models in vitro and in vivo.

402 TGF- $\beta_{1}$ or TGF- $\beta_{2}$ levels were significantly reduced in various human and mouse glioma 403 cells upon exposure to either ASO at low concentrations (Fig. 1A-C; Suppl Fig. 3A,B), 404 indicating that both molecules result in strong target inhibition. In contrast, AP12009 405 achieved a significant TGF- $\beta_{2}$ reduction only in the $\mu M$ range (29). Since a biologically 406 meaningful TGF- $\beta$ inhibition should lead to a reduction of canonical SMAD-dependent 407 signaling, we initially examined this pathway in several glioma cell lines. Both ASO 408 reduced SMAD2 phosphorylation more potently than TGF- $\beta$ RI kinase inhibition by SD409208 (Fig. 1D), denoting a potential benefit of these novel ASO in targeting TGF-B/SMAD 
410 signaling against adenosine tri-phosphate (ATP)-competitive inhibitors in vitro. In line with 411 our findings, another approach targeting TGF- $\beta$ ligands using adenoviral transfer of 412 soluble TGFBRI and II, resulted in an almost complete reduction of pSMAD2 levels in 413 glioma cells (30). Indirect approaches against the TGF-B/SMAD2 signaling axis, e.g., via 414 integrin inhibition have also proven to inhibit glioma progression in preclinical models 415 (11,31). lintegrin $\alpha v \beta 8$ is upregulated in high grade gliomas and plays a crucial role in 416 TGF- $\beta_{1}$ activation and subsequent SMAD2 signaling. av $\beta 8$ inhibition decreased both

417 TGF- $\beta_{1 / 2}$ bioavailability inducing almost complete SMAD2 dephosphorylation in LN-308 418 and LN-229 glioma cells (11). In the current study we show that blocking either TGF- $\beta_{1}$ 419 or TGF- $\beta_{2}$ expression using ASO approaches, results in a similarly strong reduction of 420 pSMAD2 levels, suggesting that direct inhibition of a single isoform is sufficient to 421 abrogate TGF-B/SMAD2 signaling $(32,33)$. Although the exact mechanism for this 422 remains elusive, we conclude that depleting a single TGF- $\beta$ isoform may impair auto423 feedback loops resulting in strong reduction of PSMAD2 levels, despite the presence of 424 other isoforms $(26,34,35)$. While similar suppression was detected at the level of another 425 canonical target, PSMAD3, less activity was seen when exploring pAKT as a 426 representative non-canonical target of TGF- $\beta$, yet, non-canonical signaling in response 427 to TGF- $\beta$ is less prominent in our models (Fig. 1E,F). We have recently revealed an 428 unexpected role for TGF- $\beta_{3}$ in the regulation of downstream TGF- $\beta$ signaling despite high 429 expression of the other two isoforms in glioblastoma (26). Here, blocking TGF- $\beta_{1}$ or TGF$430 \beta_{2}$ expression influenced TGF- $\beta_{3}$ expression only in LN-229 glioma cells (Fig. 1C). This 431 was also the cell line that exhibited the least potent pSMAD2 reduction after exposure to 432 ISTH1047 or ISTH0047 in vitro (Fig. 1F), supporting the notion that TGF- $\beta_{3}$ may 
433 compensate for the loss of other isoforms to regulate TGF- $\beta$ signaling (26). We therefore

434 hypothesize that the effects of TGF- $\beta$ isoform-specific inhibition on canonical and non-

435 canonical pathways may be cell-dependent and do not solely rely on the basal expression

436 of either TGF- $\beta_{1}$ or TGF- $\beta_{2}$ alone, but also on the potential availability of counter-

437 regulatory pathways.

438 Exposure of glioma cells to ISTH1047 or ISTH0047 did not affect cell viability (Suppl. Fig.

439 4), although SMA-560 glioma cells transfected with the TGF- $\beta_{1}$-specfic ASO displayed

440 reduced clonogenic survival, also resulting in lack of spheroid formation for assessment

441 of invasive potential in vitro (Suppl. Fig. 4D). Ashley et al. (1998) also reported growth-

442 suppressive properties of TGF- $\beta_{1}$ inhibition in SMA-560 cells and the induction of

443 apoptosis, indicating a potential survival dependency of these cells specifically related to

444 TGF- $\beta_{1}(35)$. Reduced migration and invasion of glioma cells upon TGF- $\beta / S M A D$ singling

445 blockade has been widely shown $(12,14,36)$. Correlating with the greater pSMAD2 down-

446 regulation after ASO-mediated TGF- $\beta_{1}$ or TGF- $\beta_{2}$ inhibition (Fig. 1D; Suppl Fig. 3C,D),

447 these agents also exhibited more pronounced inhibitory effects on the migratory and

448 invasive potential of glioma cells compared to TGF- $\beta$ RI kinase inhibition (Fig. 2). The high

449 binding affinity of LNA-modified ASO to cell surface proteins, such as heparin, can

450 potentiate their cellular uptake via absorptive endocytosis and consequent target

451 inhibition $(37,38)$, and combined with the irreversible nature of ASO-mediated target

452 silencing (39), may explain the superiority of these agents over small molecule ATP-

453 competitive TGF- $\beta$ R kinase inhibitors $(12,40)$ observed here.

454 Since drug delivery to gliomas is one of the limiting factors of current novel therapeutic 455 approaches administered systemically (41), we assessed whether these second- 
456 generation ASO reach the tumor site after systemic treatment in orthotopic murine glioma

457 models in vivo. Indeed, systemic subcutaneous administration of DIG-labelled ISTH1047

458 resulted in a strong oligonucleotide accumulation in the tumors with minimal deposition in

459 the normal contralateral hemisphere (Fig. 3E). Even though in vivo oligonucleotide uptake

460 pathways are currently poorly understood, LNA modifications are known to improve the

461 pharmacokinetic properties of ASO, facilitating prolonged tissue half-life and more

462 efficient cellular uptake compared to AP12009 or other first generation ASO (18). The

463 only other approach to directly inhibit TGF- $\beta$ ligand activity represents the intravenous

464 administration of the pan-TGF- $\beta$ neutralizing antibody, 1D11 that also appears to

465 selectively accumulate in the tumor (15). Systemic treatment of glioma-bearing mice with

466 either of the two ASO molecules resulted in a ligand-specific down-regulation and

467 reduction of the SMAD-dependent target gene PAl1 in the tumor-bearing hemisphere

468 (Fig. 3F,G). Given that TGF- $\beta_{1}$ and TGF- $\beta_{2}$ expression strongly correlate with PAl1

469 expression in The Cancer Genome Atlas (TCGA) analyses (6), this profound reduction in

470 TGF- $\beta$ and PAl1 levels demonstrates that isoform-specific targeting of TGF- $\beta$ is feasible

471 and interferes with TGF- $\beta$ signaling in the tumor following systemic administration. TGF-

$472 \beta_{1 / 2}$ levels were up-regulated in the tumor compared to normal brain in both glioma models

473 (Fig. 3F) supporting the notion that TGF- $\beta$ is highly expressed in glioblastoma $(5,6)$.

474 However, we did not detect any increase in tumoral TGF- $\beta_{2}$ compared to normal brain

475 tissue in SMA-560-bearing mice. The inherent low TGF- $\beta_{2}$ expression levels of SMA-560

476 gliomas have been described before (13), which may not allow for the discrimination of

477 such changes at the mRNA level between tumoral and normal tissue. TGF- $\beta_{2}$ levels in

478 SMA-560-bearing mice were reduced only after ISTH0047 treatment further supporting 
479 the specificity and efficacy of these ASO in the glioma setting (Fig. 3F). Reduced TGF- $\beta_{1}$

480 or TGF- $\beta_{2}$ levels resulted in a significant reduction of tumor invasiveness in vivo (Suppl.

481 Fig. 8), and are in line with our in vitro observations of reduced invasive potential (Fig.

$4822 \mathrm{C}, \mathrm{D})$, enhancing the importance of the TGF- $\beta / S M A D$ pathway as a major mediator of 483 glioma cell invasion $(12,42,43)$.

484 Based on these promising data, we determined the anti-glioma activity of both novel 485 antisense molecules in vivo. ISTH1047 or ISTH0047 treatment significantly reduced 486 tumor volumes and ultimately prolonged the survival of LN-308 or SMA-560 glioma487 bearing mice (Fig. 4A,B,G,H). Consistent with the TGF- $\beta$ and PAl1 mRNA inhibition data, 488 pSMAD2 levels were significantly reduced by ISTH1047 or ISTH0047 in both models (Fig. $4895 \mathrm{~A}, \mathrm{~B}, \mathrm{E}, \mathrm{F})$. A recent study with the TGF- $\beta R \mathrm{R}$ antagonist, galunisertib, as monotherapy 490 showed a marginal survival benefit in the SMA-560 model, while it did not significantly 491 affect tumor size (13). Moreover, the 1D11 pan-TGF- $\beta$-neutralizing antibody resulted in 492 an almost complete tumor remission when administered daily in immunocompetent mice 493 bearing subcutaneous gliomas but, the opposite effect was noted when it was given to 494 immunodeficient glioma-bearing mice, additionally, 1D11 failed to show a therapeutic 495 effect in an orthotopic glioma model (15). Our ASO-mediated approach utilized a twice 496 weekly dosage regime after the initial 5-day ASO treatment and led to a striking decrease 497 of pSMAD2 levels and significant tumor size reduction in the xenogeneic LN-308-bearing 498 and the syngeneic SMA-560-bearing glioma models. In LN-229-bearing mice, a 499 significant survival benefit was only observed after ISTH0047 treatment without any 500 reduction in tumor burden which, however, was assessed at a very early point in time 501 which limits the significance of this finding (Fig. 4C,D). LN-229 gliomas exhibit a highly 
502 invasive phenotype that could only be mitigated by ISTH0047-mediated TGF- $\beta_{2}$ inhibition 503 and not by ISTH1047 (Suppl. Fig. 8). Moreover, pSMAD2 expression was almost 504 eliminated after ISTH0047 treatment suggesting that TGF- $\beta_{2}$ inhibition has a potent effect 505 on the TGF- $\beta$ pathway in this model (Fig. 5C,D). Therefore, it may be that the survival 506 benefit observed with ISTH0047 in this model is mainly due to the potent reduction of 507 tumor infiltration and invasion (42), further supporting the cell-dependent effects of TGF$508 \beta$ isoform inhibition noted in our in vitro studies. We did not observe a significant survival 509 benefit upon ASO treatment in the GIC model in vivo. However, TGF- $\beta_{2}$ inhibition 510 significantly reduced tumor volume and had the better survival outcome compared to $511 T G F-\beta_{1}$ inhibition (Fig. 4E,F). In line with this finding, TGF- $\beta_{2}$ is known to be an essential 512 regulator of the self-renewing and tumor propagating capacity of patient-derived GIC (44).

513 Therefore, a more intensive ISTH0047 treating regime has the potential to exert more 514 prominent survival benefit in GIC tumor mouse models.

515 Since TGF- $\beta$ is a multifunctional cytokine with major immunosuppressive properties, we 516 assessed the host cell responses to ASO-mediated TGF- $\beta_{1}$ or TGF- $\beta_{2}$ inhibition in the 517 syngeneic, immunocompetent SMA-560 glioma model. We noted enhanced immune cell 518 infiltration in the tumor after ASO treatment. More specifically, the cytotoxic CD45 ${ }^{+}$CD8 ${ }^{+}$ 519 T-cell population was significantly increased after either ISTH1047 or ISTH0047 520 treatment (Fig. 6C). The enhanced tumor infiltration with cytotoxic $T$ cells suggests that 521 TGF- $\beta$ depletion allows for an activation of the adaptive anti-tumor immune response. 522 Interestingly, pSMAD2 depletion correlates with the increased tumoral cytotoxic T cell 523 infiltration supporting the notion that targeting TGF- $\beta$ signaling in tumors can restore 524 immune surveillance $(13,45)$. Finally, ISTH0047 treatment resulted in a significantly 
525 reduced number of $\mathrm{CD} 31^{+}$endothelial cells, suggesting that $T G F-\beta_{2}$ inhibition may reduce

526 the number of aberrant tumor blood vessels and thereby facilitate tumor vasculature

527 normalization (13). Blood vessel normalization is a process associated with a better

528 trafficking of immune cells in the tumoral bed, which may facilitate cytotoxic $\mathrm{T}$ cell

529 infiltration (46). Overall, these data indicate a potential pro-immunogenic effect of ASO-

530 mediated $T G F-\beta_{1 / 2}$ inhibition that might assist in the elimination of glioma cells, while

531 reducing their invasive and migratory abilities.

532 Except for ALAT levels marginally beyond the normal range upon treatment with

533 ISTH1047, no relevant toxicity was observed in the in vivo survival experiments (Suppl.

534 Fig. 10). However, when the two ASO molecules were administered as a combinatorial

535 treatment in the syngeneic SMA-560 glioma model, the mice exhibited severe systemic

536 toxicity and therefore this treatment arm was not selected for further investigations. For

537 reasons currently undetermined, LNA-modified ASO have been linked with an increased

538 risk of acute kidney injury in pre-clinical studies when compared to other second-

539 generation ASO variants (47). However, in vivo pre-clinical toxicology studies tend to

540 over-predict the renal effects of ASO, as these agents do not appear to exert significant

541 nephrotoxicity when tested in humans (48). Therefore, even though informative, any

542 toxicology studies performed in murine glioma models with ISTH1047 or ISTH0047 do

543 not necessarily predict the situation in glioblastoma patients. Altogether, these data show

544 that ASO-mediated TGF- $\beta$ ligand targeting represents an alternative, convenient and

545 efficient way to block the TGF- $\beta$ /SMAD pathway resulting in a significant survival benefit

546 compared to other approaches, in both the xenograft and syngeneic glioma setting in

547 vivo. 
548 The present dataset strongly suggests that TGF- $\beta$ retains an important role in

549 glioblastoma progression and that an efficient targeting approach can potentially improve

550 clinical outcome. We show strong therapeutic activity of two novel second-generation

551 TGF- $\beta$-specific ASO in two independent glioma models which may now allow for clinical

552 evaluation of their therapeutic potential in human patients. Given the immune-modulatory

553 activities of the two ASO molecules, a potential combination of ISTH1047 or ISTH0047

554 with immune checkpoint inhibitors that are currently explored in clinical neuro-oncology

$555(49,50)$, may result in synergistic therapeutic activity and warrants further investigation.

556

557

558

559

560

\section{Acknowledgments}

562 We thank D. Mangani for help with the initial animal studies, and Julia Friesen and

563 Franziska Wiget for the excellent technical assistance.

564

565 Funding

566 This study was supported by the Clinical Research Priority Program (CRPP) of the

567 University of Zurich for the CRPP ImmunoCure and by a grant from the Swiss National

568 Science Foundation (SNF 310030_170027) to PR.

569 
572 Figure 1. ISTH1047 and ISTH0047 interfere with TGF- $\beta$ signaling. A,B. LN-308 (A) or

573 SMA-560 (B) glioma cells were exposed to ISTH1047 or ISTH0047 at $50 \mathrm{nM}$ for $24 \mathrm{~h}$ and

574 TGF- $\beta_{1 / 2}$ protein levels in the cell culture supernatant were determined by ELISA at 48 ,

57572 or 96 h post transfection. C. LN-308, LN-229, ZH-161 or SMA-560 glioma cells were

576 exposed to ISTH1047 or ISTH0047 at $50 \mathrm{nM}$ for $24 \mathrm{~h}$ and TGF- $\beta_{1 / 2 / 3}$ mRNA levels were

577 assessed by RT-PCR $48 \mathrm{~h}$ post transfection. D,E. LN-308 or SMA-560 glioma cells were

578 exposed to ISTH1047 or ISTH0047 at $50 \mathrm{nM}$ for 24 h. pSMAD2 (D), pSMAD3, total

579 SMAD3, pAKT and total AKT (E) levels were assessed by immunoblot at $48 \mathrm{~h}$ post

580 transfection. $\mathbf{F}$. LN-229 or ZH-161 glioma cells were exposed to ISTH1047 or ISTH0047

581 at $50 \mathrm{nM}$ for 24 h. pSMAD2, total SMAD2, pSMAD3, total SMAD3, pAKT and total AKT

582 levels were assessed by immunoblot at $48 \mathrm{~h}$ post transfection. C3_ISTH0047 at $50 \mathrm{nM}$

583 was used as scrambled sequence oligonucleotide control (Ctrl). Exogenous TGF- $\beta_{1 / 2}$ (5

$584 \mathrm{ng} / \mathrm{ml}$ ) was used to induce pSMAD2 in ZH-161. The TGF- $\beta$ receptor I kinase inhibitor SD-

$585208(1 \mu \mathrm{M})$ was used as an additional control for TGF- $\beta$ pathway inhibition. Results are

586 expressed as means and SD ( $n=3)$, statistical analysis was performed with one-way

587 ANOVA and Bonferroni post-hoc testing $\left({ }^{*} p<0.05,{ }^{* *} p<0.01\right)$.

589 Figure 2. TGF- $\beta$ inhibition by ISTH1047 or ISTH0047 reduces glioma cell migration

590 and invasion. A,B. LN-308 (A) or SMA-560 (B) glioma cells were transfected with

591 ISTH1047, ISTH0047, control oligonucleotide (Ctrl) or exposed to galunisertib, SD-208 or

592 recombinant TGF- $\beta_{1 / 2}$ at the indicated concentrations for $72 \mathrm{~h}$ and then examined in

593 Transwell-Boyden chamber assays. Data are expressed as mean migrated cells per 
594 membrane. C,D. LN-308 (C) or SMA-560 (D) glioma cells transfected with $50 \mathrm{nM}$

595 ISTH1047 or ISTH0047, exposed to $1 \mu \mathrm{M}$ SD-208, $5 \mathrm{ng} / \mathrm{ml} \mathrm{TGF-} \beta_{1}$ or $5 \mathrm{ng} / \mathrm{ml} \mathrm{TGF-} \beta_{2}$ for

$59624 \mathrm{~h}$ were allowed to form spheroids in agar and seeded in collagen-I. Invasion was

597 assessed by quantifying the area of invaded cells into the collagen over $96 \mathrm{~h}$. Results are

598 expressed as means and SD ( $n=3)$, statistical analysis was performed with one-way 599 ANOVA and Bonferroni post-hoc testing $\left({ }^{*} p<0.05\right)$.

600

601 Figure 3. ASO are detected at the tumor site upon systemic administration and 602 inhibit TGF- $\beta_{1}$ or TGF- $\beta_{2}$ expression in orthotopically growing gliomas in vivo. LN-

$603308\left(10^{5}\right)$ or SMA-560 $\left(5 \times 10^{3}\right)$ glioma cells were injected stereotactically into the right 604 hemisphere of Crl: CD1 Foxn1 or VM/Dk mice, respectively. A-E. Twenty-five or five days 605 after tumor inoculation for Crl: CD1 Foxn1 or VM/Dk mice, respectively, systemic 606 treatment with DIG-ISTH1047 (10 mg/kg) was initiated for 5 consecutive days. Two days 607 following the last injection, brains from LN-308 (A) or SMA-560 (B) glioma-bearing mice 608 were collected and histologically assessed for DIG expression in the tumor region using 609 an anti-mouse DIG antibody. Representative images of DIG fluorescence staining in LN$610308(\mathbf{A})$ or SMA-560 (B) tumors are shown (DIG, green; nuclei staining with DAPI, blue).

611 Contralateral normal brain hemisphere was used as additional control (C). Mouse IgG 612 was used as a negative control (D). Mean fluorescence intensity was quantified using the 613 Bitplane Imaris software (E). Results are expressed as means and SD ( $n=3)$, statistical 614 analysis was performed with one-way ANOVA and Bonferroni post-hoc testing $\left({ }^{*} p<0.05\right.$, $\left.615{ }^{* *} p<0.01\right)$. F, G. Twenty-five or five days after tumor inoculation for Crl: CD1 Foxn1 or 616 VM/Dk mice, respectively, systemic treatment with C3_ISTH0047 (Ctrl) (20 mg/kg), 
617 ISTH1047 (10 mg/kg) or ISTH0047 (20 mg/kg) was initiated for 5 consecutive days. Two 618 days following the last injection, tumor- and non-tumor-bearing (normal) hemispheres 619 from LN-308 or SMA-560 glioma-bearing mice were collected and assessed for TGF- $\beta_{1}$, 620 TGF- $\beta_{2}, T G F-\beta_{3}$ or PAl1 mRNA expression using RT-qPCR. Human-specific TGF- $\beta_{1}$, $621 T G F-\beta_{2}, T G F-\beta_{3}$ or $P A / 1$ primer sequences were used to assess target gene expression 622 in LN-308-derived tumors. Results are expressed as means and SD ( $n=4)$, statistical 623 analysis was performed with one-way ANOVA and Bonferroni post-hoc testing $(p<0.05$;

$624{ }^{*}=$ control vs treatment in tumor tissue $;^{+}=$control vs treatment in normal tissue; ${ }^{\#}=$ 625 normal tissue vs. tumor tissue).

626

627 Figure 4. Systemic treatment of glioma-bearing mice with ISTH1047 or ISTH0047 628 inhibits tumor growth and prolongs survival. A-H. LN-308 $\left(10^{5}\right), \mathrm{LN}-229\left(10^{5}\right), \mathrm{ZH}-$ $629161\left(10^{5}\right)$ or SMA-560 $\left(5 \times 10^{3}\right)$ glioma cells were injected stereotactically into the right 630 hemisphere of Crl: CD1 Foxn1 or VM/Dk mice, respectively. Twenty-five (LN-308), ten 631 (LN-229, ZH-161) or five days (SMA-560) after tumor inoculation, systemic treatment with 632 C3_ISTH0047 (Ctrl) (20 mg/kg), ISTH1047 (10 mg/kg) or ISTH0047 (20 mg/kg) was 633 initiated for 5 consecutive days. Agents were administered twice weekly thereafter. Mice 634 were sacrificed when they developed grade 2 neurological symptoms. Survival curves for 635 LN-308 (A), LN-229 (C), ZH-161 (E) and SMA-560 (G) were analyzed for differences via 636 log-rank (Martel-Cox) test at ${ }^{*} p<0.05$ and ${ }^{* *} p<0.01$. Brains from three pre-randomized 637 LN-308 (B), LN-229 (D), ZH-161 (F) or SMA-560 (H) glioma-bearing mice per group were 638 subjected to for histological analyses when the first mouse developed clinical symptoms. 639 Tumor volumes were determined using the ellipsoid geometric primitive formula. Results 
640 (B,D,F,H) are expressed as means and SD $(n=3)$, statistical analysis was performed with 641 one-way ANOVA and Bonferroni post-hoc testing $\left({ }^{*} p<0.05\right)$.

642

643 Figure 5. ISTH1047 or ISTH0047 treatment reduces tumoral SMAD2 644 phosphorylation. A-F. LN-308 $\left(10^{5}\right)$, LN-229 $\left(10^{5}\right)$ or SMA-560 $\left(5 \times 10^{3}\right)$ glioma cells were 645 injected stereotactically into the right hemisphere of Crl: CD1 Foxn1 or VM/Dk mice, 646 respectively. Twenty-five (LN-308), ten (LN-229) or five days (SMA-560) after tumor 647 inoculation, systemic treatment with C3_ISTH0047 (Ctrl) $(20 \mathrm{mg} / \mathrm{kg})$, ISTH1047 (10 $648 \mathrm{mg} / \mathrm{kg})$ or ISTH0047 (20 mg/kg) was initiated for 5 consecutive days and then 649 administered twice weekly. Brains from LN-308 (A,B), LN-229 (C,D) or SMA-560 (E,F) 650 glioma-bearing mice were extracted for histological analyses from three pre-randomized 651 animals per group when the first mouse developed clinical symptoms to assess pSMAD2

652 levels. Representative images of pSMAD2 stainings of LN-308 (A), LN-229 (C) or SMA653 560-derived (E) tumors are shown (pSMAD2, green; nuclei staining with DAPI, blue).

654 Mean fluorescence intensity (B,D,F) was quantified using the Bitplane Imaris software. 655 Results (B,D,F) are expressed as means and SD ( $n=2-3)$, statistical analysis was 656 performed with one-way ANOVA and Bonferroni post-hoc testing $\left({ }^{*} p<0.05\right)$.

657

658 Figure 6. Modulation of tumor immune cell infiltration in ISTH1047- or ISTH0047659 treated syngeneic SMA-560-bearing mice. A-E. SMA-560 $\left(5 \times 10^{3}\right)$ glioma cells were 660 injected stereotactically into the right hemisphere of VM/Dk mice. Five days after tumor 661 inoculation, systemic treatment with C3_ISTH0047 (Ctrl) $(20$ mg/kg), ISTH1047 (10 $662 \mathrm{mg} / \mathrm{kg})$ or ISTH0047 (20 mg/kg) was initiated for 5 consecutive days and then 
663 administered twice weekly. Brains from glioma-bearing mice were extracted for 664 histological analyses from three pre-randomized animals per group when the first mouse 665 developed clinical symptoms to detect CD45+ leukocyte (A), CD3 ${ }^{+} \mathrm{T}$ cell $(\mathbf{B}), \mathrm{CD}^{+}$ 666 cytotoxic T cell (C), CD4+ T helper cell (D) or CD11 b+ monocyte/microglia (E) populations. 667 Results are expressed as means and SD $(n=12)$, statistical analysis was performed with 668 one-way ANOVA and Bonferroni post-hoc testing $\left({ }^{*} p<0.05,{ }^{* *} p<0.01\right)$.

669

670

671

672

673

674

675

676

677

678

679

680

681

682

683

684

685

686

687 


\section{References}

689 1. Weller M, van den Bent M, Tonn JC, Stupp R, Preusser M, Cohen-Jonathan-Moyal E, et 690 al. European Association for Neuro-Oncology (EANO) guideline on the diagnosis and 691 treatment of adult astrocytic and oligodendroglial gliomas. The Lancet Oncology 692 2017;18(6):e315-e29.

693 2. Hinck AP. Structural studies of the TGF-betas and their receptors - insights into evolution 694 of the TGF-beta superfamily. FEBS letters 2012;586(14):1860-70.

695 3. Massague J. TGF[beta] signalling in context. Nat Rev Mol Cell Biol 2012;13(10):616-30.

696 4. Pickup M, Novitskiy S, Moses HL. The roles of TGF[beta] in the tumour microenvironment. $697 \quad$ Nat Rev Cancer 2013;13(11):788-99.

698 5. Bruna A, Darken RS, Rojo F, Ocana A, Penuelas S, Arias A, et al. High TGFbeta-Smad 699 activity confers poor prognosis in glioma patients and promotes cell proliferation 700 depending on the methylation of the PDGF-B gene. Cancer Cell 2007;11(2):147-60.

701 6. Frei K, Gramatzki D, Tritschler I, Schroeder JJ, Espinoza L, Rushing EJ, et al. 702 Transforming growth factor-beta pathway activity in glioblastoma. Oncotarget 2015;6(8):5963-77.

704 7. Hardee ME, Marciscano AE, Medina-Ramirez CM, Zagzag D, Narayana A, Lonning SM, 705 et al. Resistance of glioblastoma-initiating cells to radiation mediated by the tumor 706 microenvironment can be abolished by inhibiting transforming growth factor-beta. Cancer $707 \quad$ Res 2012;72(16):4119-29.

708 8. Liu S, Sun J, Lan Q. TGF-beta-induced miR10a/b expression promotes human glioma cell 709 migration by targeting PTEN. Molecular medicine reports 2013;8(6):1741-6.

710 9. Stander M, Naumann U, Dumitrescu L, Heneka M, Loschmann P, Gulbins E, et al. Decorin 711 gene transfer-mediated suppression of TGF-beta synthesis abrogates experimental 712 malignant glioma growth in vivo. Gene therapy 1998;5(9):1187-94. 
713 10. Ventura E, Weller M, Burghardt I. Cutting Edge: ERK1 Mediates the Autocrine Positive

714 Feedback Loop of TGF-beta and Furin in Glioma-Initiating Cells. Journal of immunology

715 (Baltimore, Md : 1950) 2017;198(12):4569-74.

716 11. Roth P, Silginer M, Goodman SL, Hasenbach K, Thies S, Maurer G, et al. Integrin control 717 of the transforming growth factor-beta pathway in glioblastoma. Brain : a journal of 718 neurology 2013;136(Pt 2):564-76.

719 12. Uhl M, Aulwurm S, Wischhusen J, Weiler M, Ma JY, Almirez R, et al. SD-208, a novel 720 transforming growth factor beta receptor I kinase inhibitor, inhibits growth and 721 invasiveness and enhances immunogenicity of murine and human glioma cells in vitro and 722 in vivo. Cancer Res 2004;64(21):7954-61.

723 13. Mangani D, Weller M, Seyed Sadr E, Willscher E, Seystahl K, Reifenberger G, et al. 724 Limited role for transforming growth factor-beta pathway activation-mediated escape from 725 VEGF inhibition in murine glioma models. Neuro Oncol 2016;18(12):1610-21.

726 14. Zhang M, Kleber S, Rohrich M, Timke C, Han N, Tuettenberg J, et al. Blockade of TGF727 beta signaling by the TGFbetaR-I kinase inhibitor LY2109761 enhances radiation response and prolongs survival in glioblastoma. Cancer Res 2011;71(23):7155-67.

729 15. Hulper P, Schulz-Schaeffer W, Dullin C, Hoffmann P, Harper J, Kurtzberg L, et al. Tumor 730 localization of an anti-TGF-beta antibody and its effects on gliomas. International journal 731 of oncology 2011;38(1):51-9.

732 16. Brandes AA, Carpentier AF, Kesari S, Sepulveda-Sanchez JM, Wheeler HR, Chinot O, et 733 al. A Phase II randomized study of galunisertib monotherapy or galunisertib plus lomustine 734 compared with lomustine monotherapy in patients with recurrent glioblastoma. Neuro $735 \quad$ Oncol 2016;18(8):1146-56.

736 17. Rodon J, Carducci MA, Sepulveda-Sanchez JM, Azaro A, Calvo E, Seoane J, et al. First737 in-human dose study of the novel transforming growth factor-beta receptor I kinase 738 inhibitor LY2157299 monohydrate in patients with advanced cancer and glioma. Clinical 
cancer research : an official journal of the American Association for Cancer Research 2015;21(3):553-60.

741 18. Khorkova O, Wahlestedt C. Oligonucleotide therapies for disorders of the nervous system. Nat Biotech 2017;35(3):249-63.

743 19. Moreno PMD, Pêgo AP. Therapeutic antisense oligonucleotides against cancer: hurdling to the clinic. Frontiers in Chemistry 2014;2:87.

745 20. Bogdahn U, Hau P, Stockhammer G, Venkataramana NK, Mahapatra AK, Suri A, et al. 746 Targeted therapy for high-grade glioma with the TGF-beta2 inhibitor trabedersen: results 747 of a randomized and controlled phase llb study. Neuro Oncol 2011;13(1):132-42.

748 21. Evers MM, Toonen LJA, van Roon-Mom WMC. Antisense oligonucleotides in therapy for 749 neurodegenerative disorders. Advanced Drug Delivery Reviews 2015;87:90-103.

750 22. Wahlestedt C, Salmi P, Good L, Kela J, Johnsson T, Hokfelt T, et al. Potent and nontoxic 751 antisense oligonucleotides containing locked nucleic acids. Proceedings of the National 752 Academy of Sciences of the United States of America 2000;97(10):5633-8.

753 23. Serano RD, Pegram CN, Bigner DD. Tumorigenic cell culture lines from a spontaneous $754 \quad$ VM/Dk murine astrocytoma (SMA). Acta neuropathologica 1980;51(1):53-64.

755 24. Le Rhun E, von Achenbach C, Lohmann B, Silginer M, Schneider H, Meetze K, et al. 756 Profound, durable and MGMT-independent sensitivity of glioblastoma cells to cyclin-

758 25. Silginer M, Burghardt I, Gramatzki D, Bunse L, Leske H, Rushing EJ, et al. The aryl 759 760 hydrocarbon receptor links integrin signaling to the TGF-beta pathway. Oncogene 761 762 763 2016;35(25):3260-71.

26. Seystahl K, Papachristodoulou A, Burghardt I, Schneider H, Hasenbach K, Janicot M, et al. Biological Role and Therapeutic Targeting of TGF-beta3 in Glioblastoma. Mol Cancer Ther 2017;16(6):1177-86. 
764 27. Akiyoshi S, Ishii M, Nemoto N, Kawabata M, Aburatani H, Miyazono K. Targets of transcriptional regulation by transforming growth factor-beta: Expression profile analysis using oligonucleotide arrays. Jpn J Cancer Res 2001;92(3):257-68.

767 28. Vester B, Wengel J. LNA (locked nucleic acid): high-affinity targeting of complementary RNA and DNA. Biochemistry 2004;43(42):13233-41.

769 29. Hau P, Jachimczak P, Schlingensiepen R, Schulmeyer F, Jauch T, Steinbrecher A, et al. Inhibition of TGF-beta 2 with AP 12009 in recurrent malignant gliomas: From preclinical to phase I/II studies. Oligonucleotides 2007;17(2):201-12.

772 30. Naumann U, Maass P, Gleske AK, Aulwurm S, Weller M, Eisele G. Glioma gene therapy 773 with soluble transforming growth factor-beta receptors II and III. International journal of oncology 2008;33(4):759-65.

775 31. Guerrero PA, Tchaicha JH, Chen Z, Morales JE, McCarty N, Wang Q, et al. Glioblastoma 776

32. Zhang K, Liu X, Hao F, Dong A, Chen D. Targeting TGF-beta1 inhibits invasion of anaplastic thyroid carcinoma cell through SMAD2-dependent S100A4-MMP-2/9 signalling. American journal of translational research 2016;8(5):2196-209.

781 33. Yin Q, Liu S, Dong A, Mi X, Hao F, Zhang K. Targeting Transforming Growth Factor-Beta1 782 (TGF-beta1) Inhibits Tumorigenesis of Anaplastic Thyroid Carcinoma Cells Through ERK1/2-NFkappakB-PUMA Signaling. Medical science monitor : international medical journal of experimental and clinical research 2016;22:2267-77.

785 34. O'Reilly MA, Danielpour D, Roberts AB, Sporn MB. Regulation of Expression of 786 Transforming Growth Factor- $\beta 2$ by Transforming Growth Factor- $\beta$ Isoforms is Dependent 787 upon Cell Type. Growth Factors 1992;6(4):193-201. 
788 35. Ashley DM, Sampson JH, Archer GE, Hale LP, Bigner DD. Local production of TGF beta1 inhibits cerebral edema, enhances TNF-alpha induced apoptosis and improves survival in a murine glioma model. Journal of neuroimmunology 1998;86(1):46-52.

791 36. Hau P, Jachimczak P, Bogdahn U. Treatment of malignant gliomas with TGF-beta2

37. Sirois $\mathrm{CM}$, Jin $\mathrm{T}$, Miller $\mathrm{AL}$, Bertheloot

$\mathrm{D}$, Nakamura $\mathrm{H}$, Horvath $\mathrm{GL}$, et al. RAGE is a nucleic acid receptor that promotes inflammatory responses to DNA. The Journal of experimental medicine 2013;210(11):2447-63.

796 38. Juliano RL, Ming X, Nakagawa O. Cellular uptake and intracellular trafficking of antisense

39. Lundin KE, Gissberg O, Smith CIE. Oligonucleotide Therapies: The Past and the Present. Human Gene Therapy 2015;26(8):475-85.

800 40. Herbertz S, Sawyer JS, Stauber AJ, Gueorguieva I, Driscoll KE, Estrem ST, et al. Clinical development of galunisertib (LY2157299 monohydrate), a small molecule inhibitor of transforming growth factor-beta signaling pathway. Drug Design, Development and

804 41. van Tellingen O, Yetkin-Arik B, de Gooijer MC, Wesseling P, Wurdinger T, de Vries HE. 805 Overcoming the blood-brain tumor barrier for effective glioblastoma treatment. Drug 806 resistance updates : reviews and commentaries in antimicrobial and anticancer

808 42. Tran TT, Uhl M, Ma JY, Janssen L, Sriram V, Aulwurm S, et al. Inhibiting TGF-beta 809 signaling restores immune surveillance in the SMA-560 glioma model. Neuro Oncol $810 \quad 2007 ; 9(3): 259-70$.

811 43. Tchaicha JH, Reyes SB, Shin J, Hossain MG, Lang FF, McCarty JH. Glioblastoma 812 angiogenesis and tumor cell invasiveness are differentially regulated by beta8 integrin. 813 Cancer Res 2011;71(20):6371-81. 
814 44. Penuelas S, Anido J, Prieto-Sanchez RM, Folch G, Barba I, Cuartas I, et al. TGF-beta 815 increases glioma-initiating cell self-renewal through the induction of LIF in human 816 glioblastoma. Cancer Cell 2009;15(4):315-27.

817 45. Rich JN. The role of transforming growth factor-beta in primary brain tumors. Front Biosci $818 \quad 2003 ; 8: \mathrm{e} 245-60$.

819 46. Liu J, Liao S, Diop-Frimpong B, Chen W, Goel S, Naxerova K, et al. TGF-beta blockade 820 improves the distribution and efficacy of therapeutics in breast carcinoma by normalizing 821 the tumor stroma. Proceedings of the National Academy of Sciences of the United States 822 of America 2012;109(41):16618-23.

823 47. Engelhardt JA. Comparative Renal Toxicopathology of Antisense Oligonucleotides. $824 \quad$ Nucleic acid therapeutics 2016;26(4):199-209.

825 48. Crooke ST, Baker BF, Kwoh TJ, Cheng W, Schulz DJ, Xia S, et al. Integrated Safety 826 Assessment of 2'-O-Methoxyethyl Chimeric Antisense Oligonucleotides in NonHuman 827 Primates and Healthy Human Volunteers. Molecular Therapy 2016;24(10):1771-82.

828 49. Bouffet E, Larouche V, Campbell BB, Merico D, de Borja R, Aronson M, et al. Immune 829 Checkpoint Inhibition for Hypermutant Glioblastoma Multiforme Resulting From Germline 830 Biallelic Mismatch Repair Deficiency. J Clin Oncol 2016;34(19):2206-11.

831 50. Weller M, Roth P, Preusser M, Wick W, Reardon DA, Platten M, et al. Vaccine-based 832 immunotherapeutic approaches to gliomas and beyond. Nature reviews Neurology $833 \quad 2017 ; 13(6): 363-74$.

834 
A

LN-308

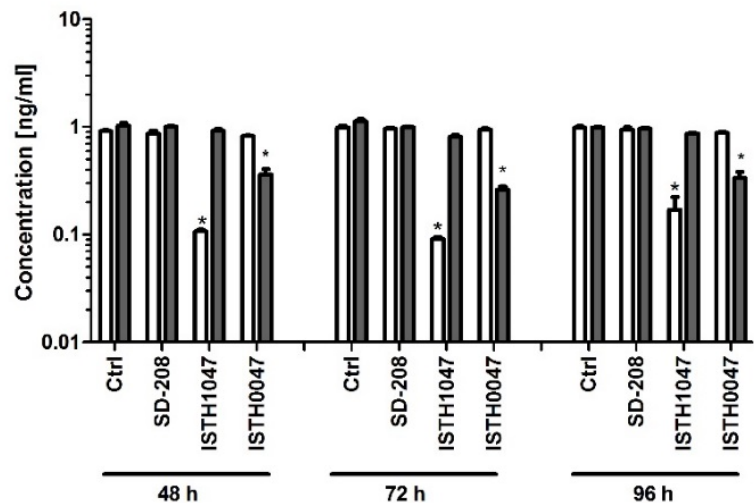

B

SMA-560

$\square$ TGF- $\beta_{1}$

$\square$ TGF- $\beta_{2}$

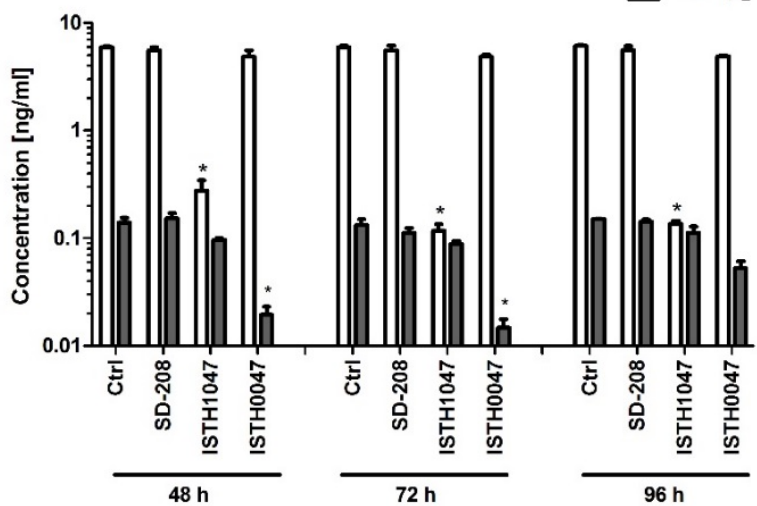

C
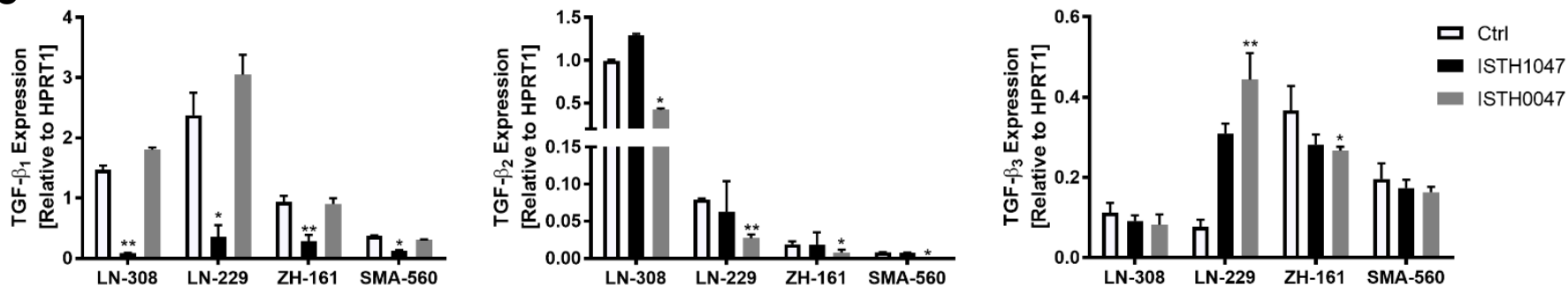

D

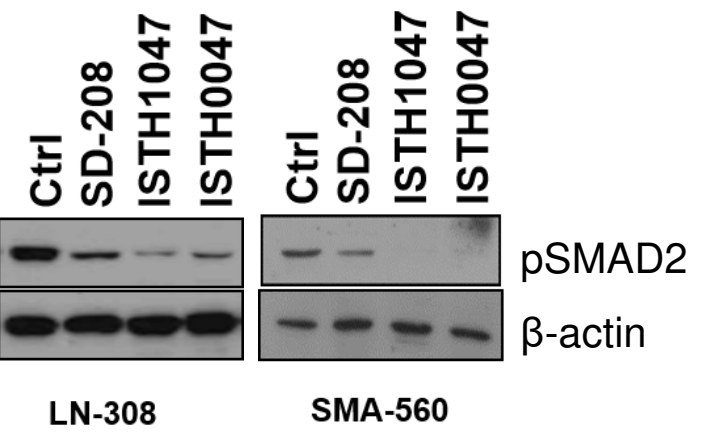

F
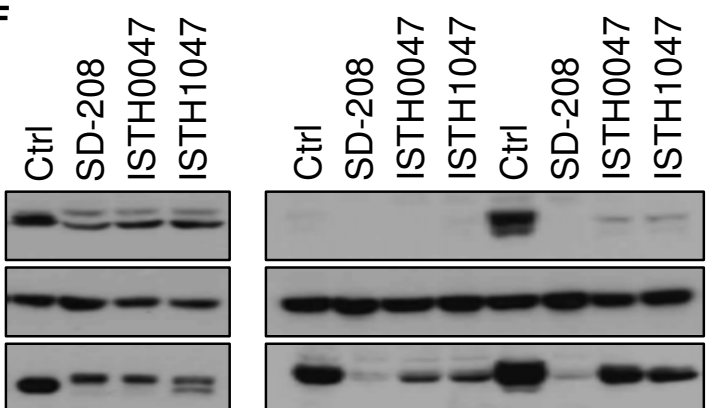

pSMAD2

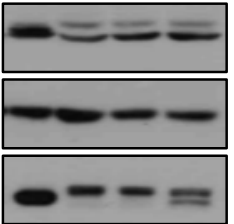

total SMAD2

pSMAD3

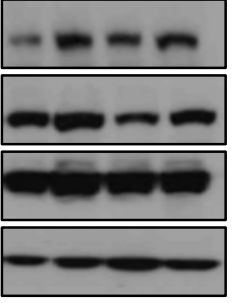

total SMAD3

LN-229

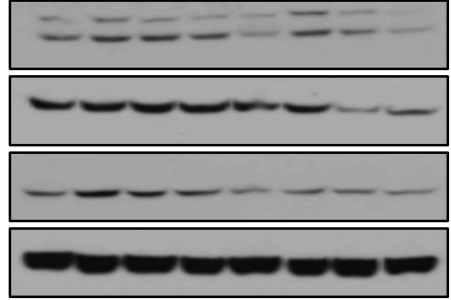

total SMAD3

pAKT

AKT

$\beta$-actin

ZH-161 pAKT AKT $\beta$-actin 
A

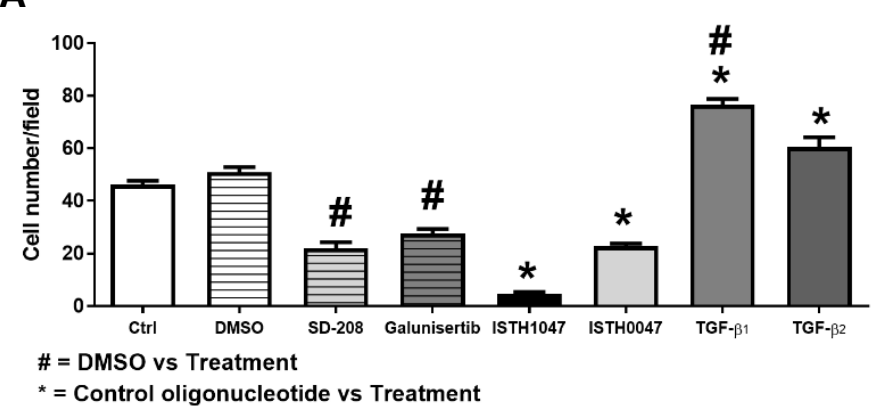

C

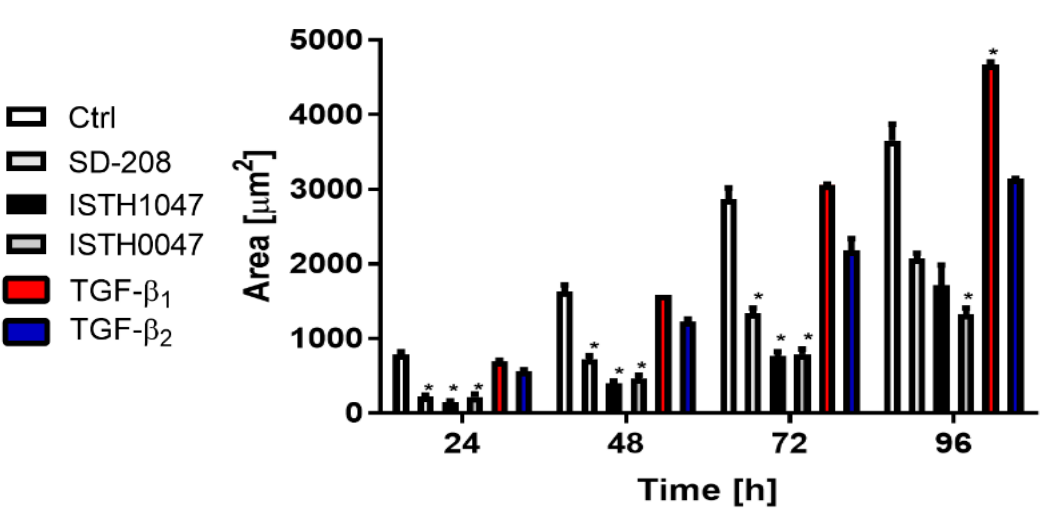

B SMA-560

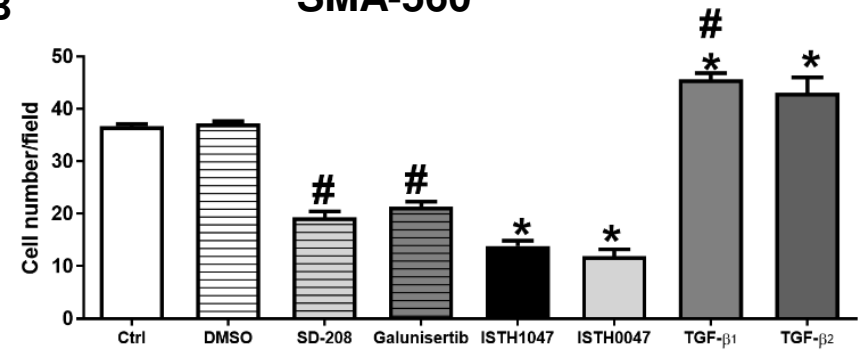

D

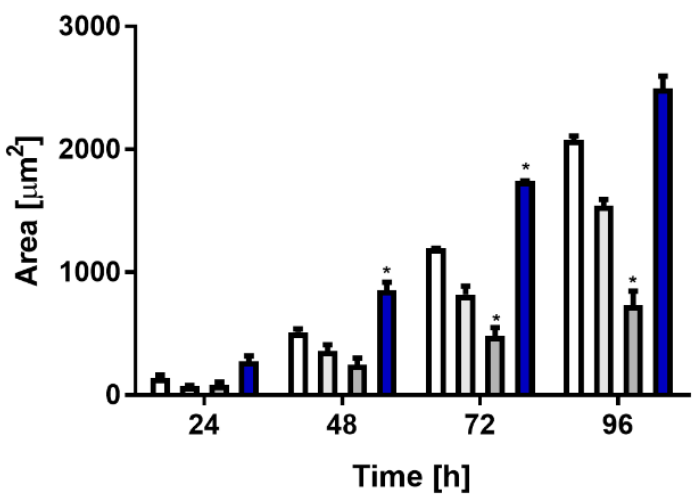

LN-308

SMA-560

Time [h] 
A

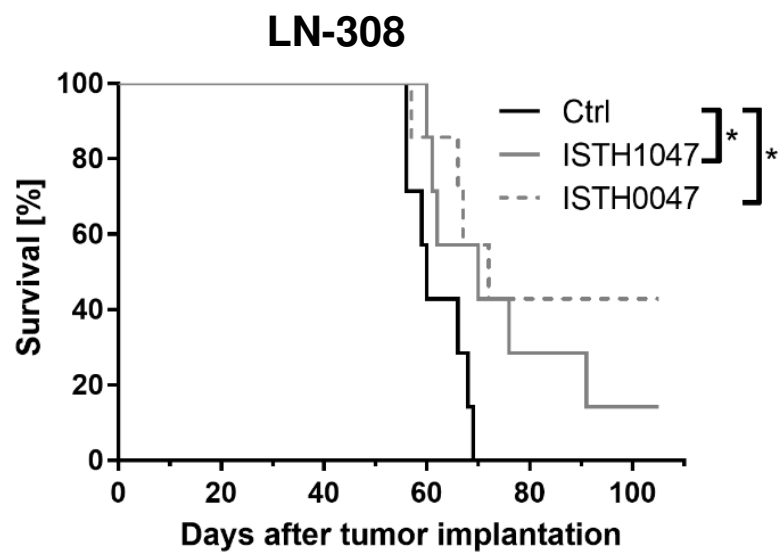

C

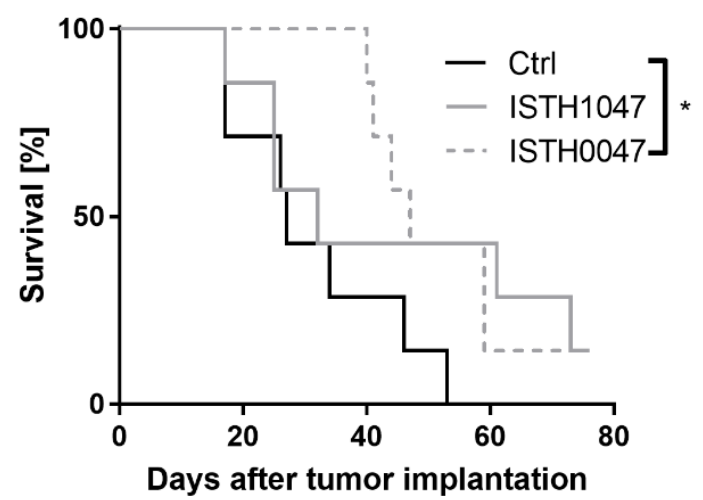

E

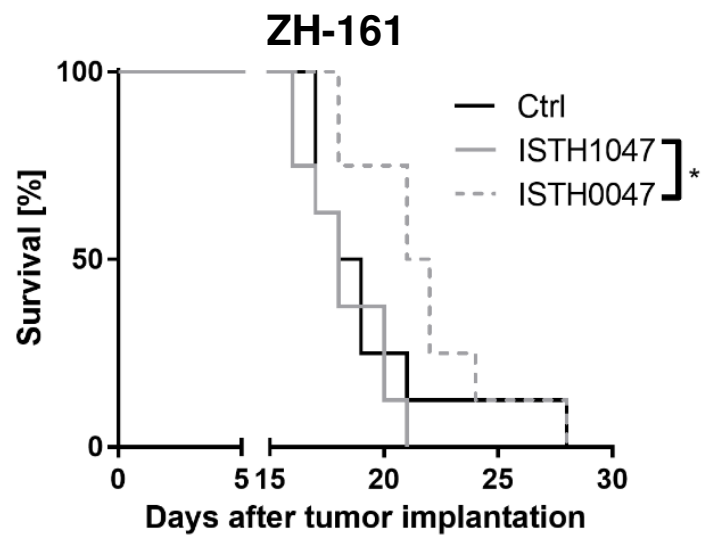

G

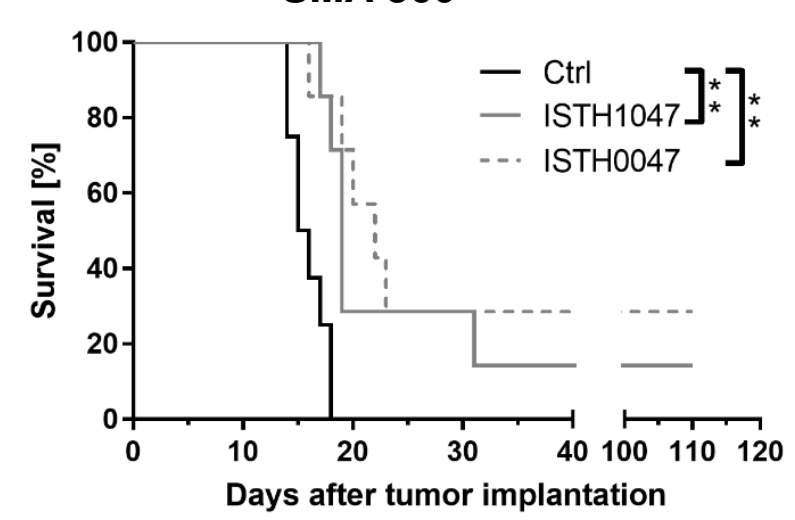

B

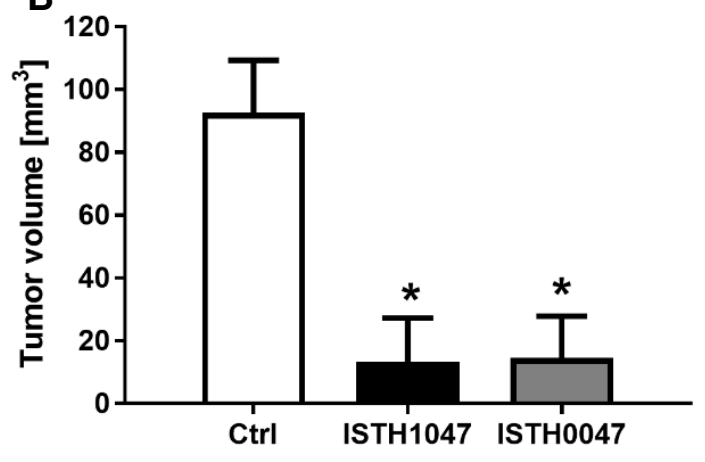

D

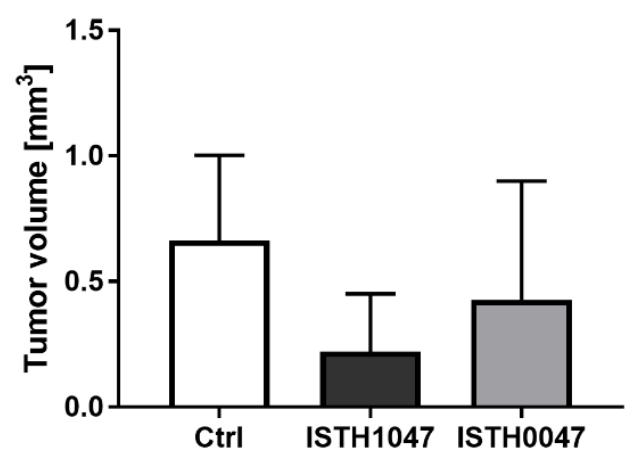

F

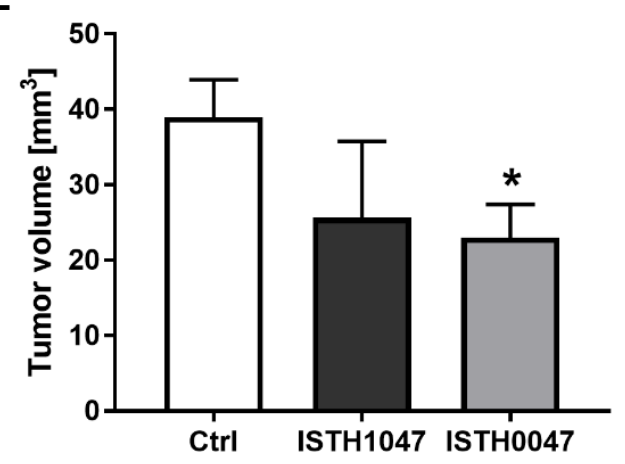

H

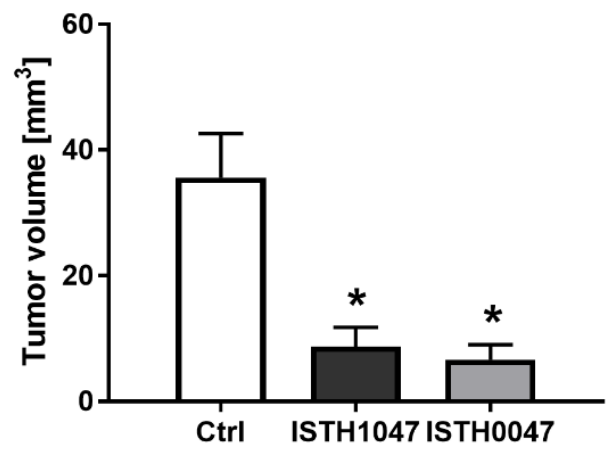



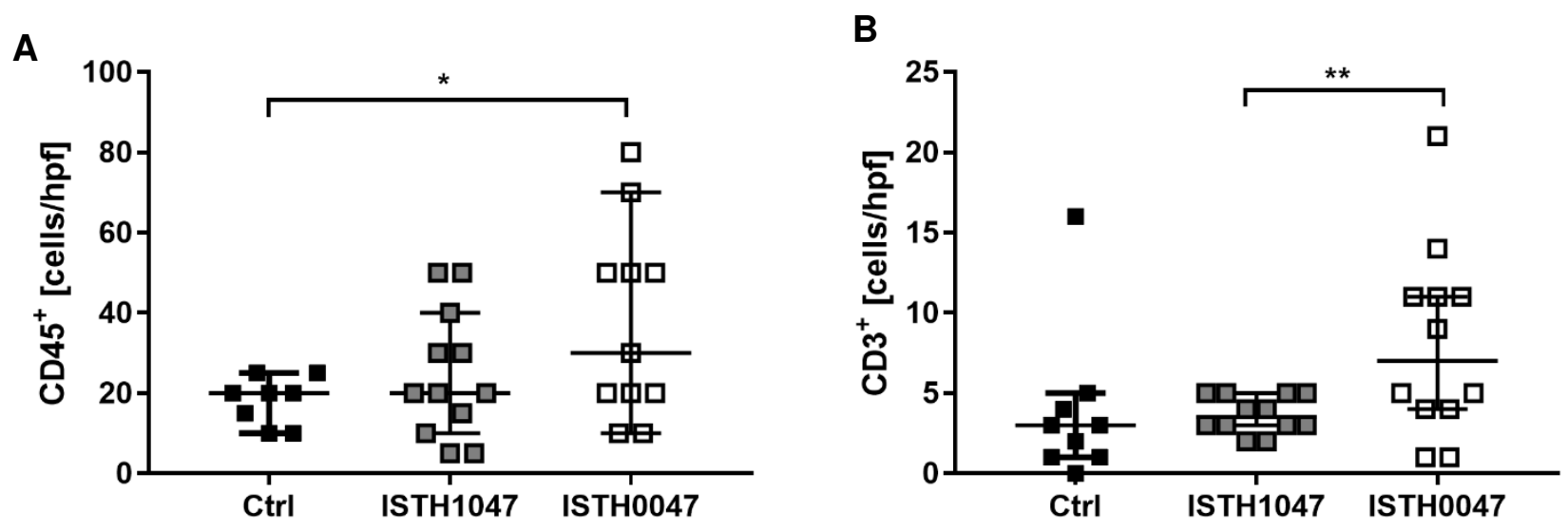

C
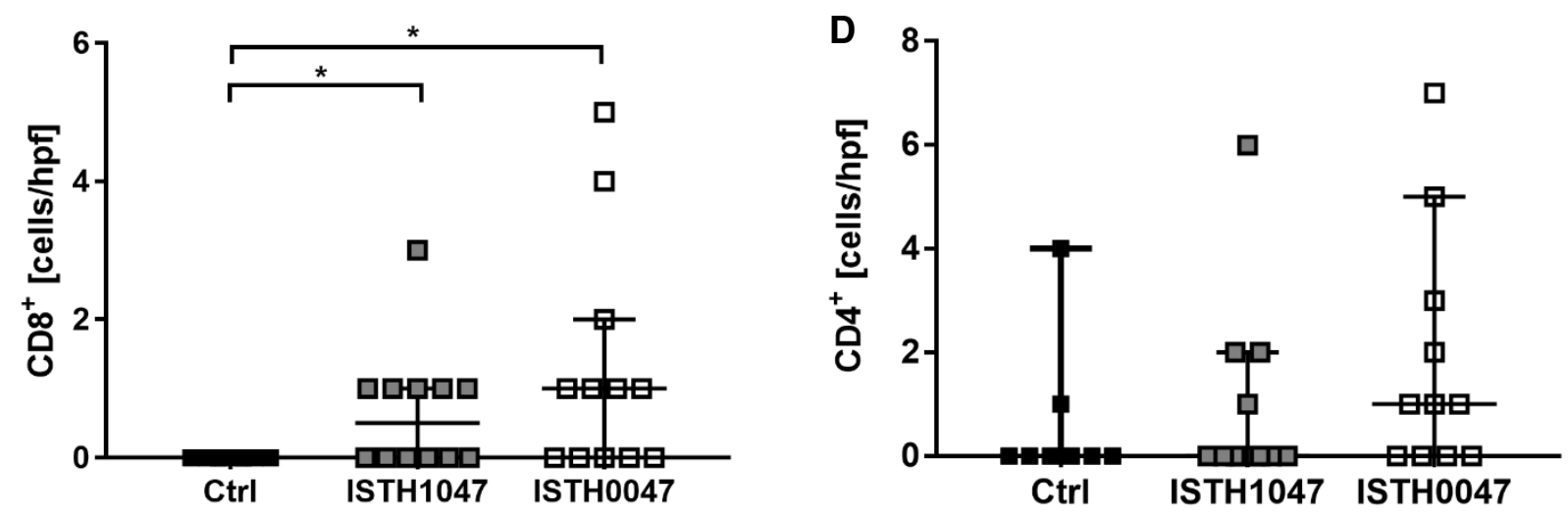

E

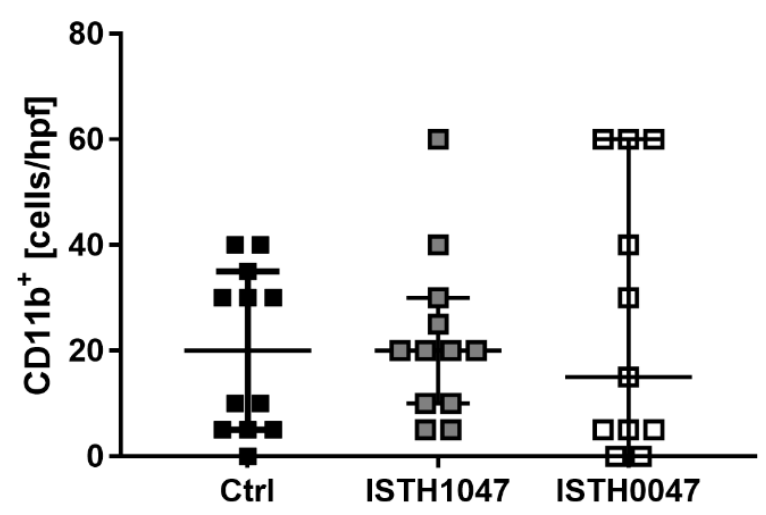




\section{A ISTH1047: 5'TCGATGCGCTTCCG-3'}

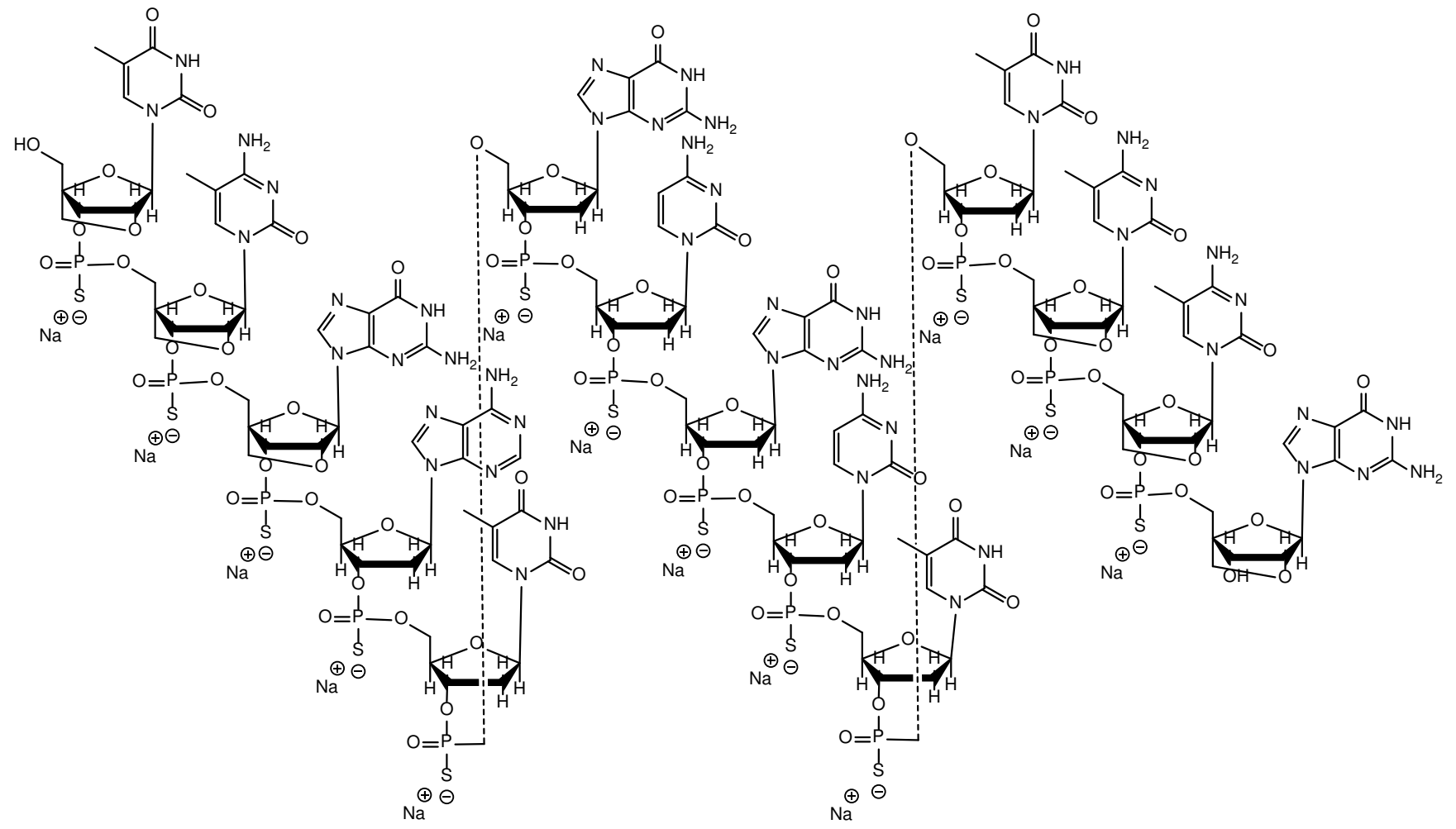

\section{B ISTH0047: 5'CAAAGTATTTGGTCTCC-3'}

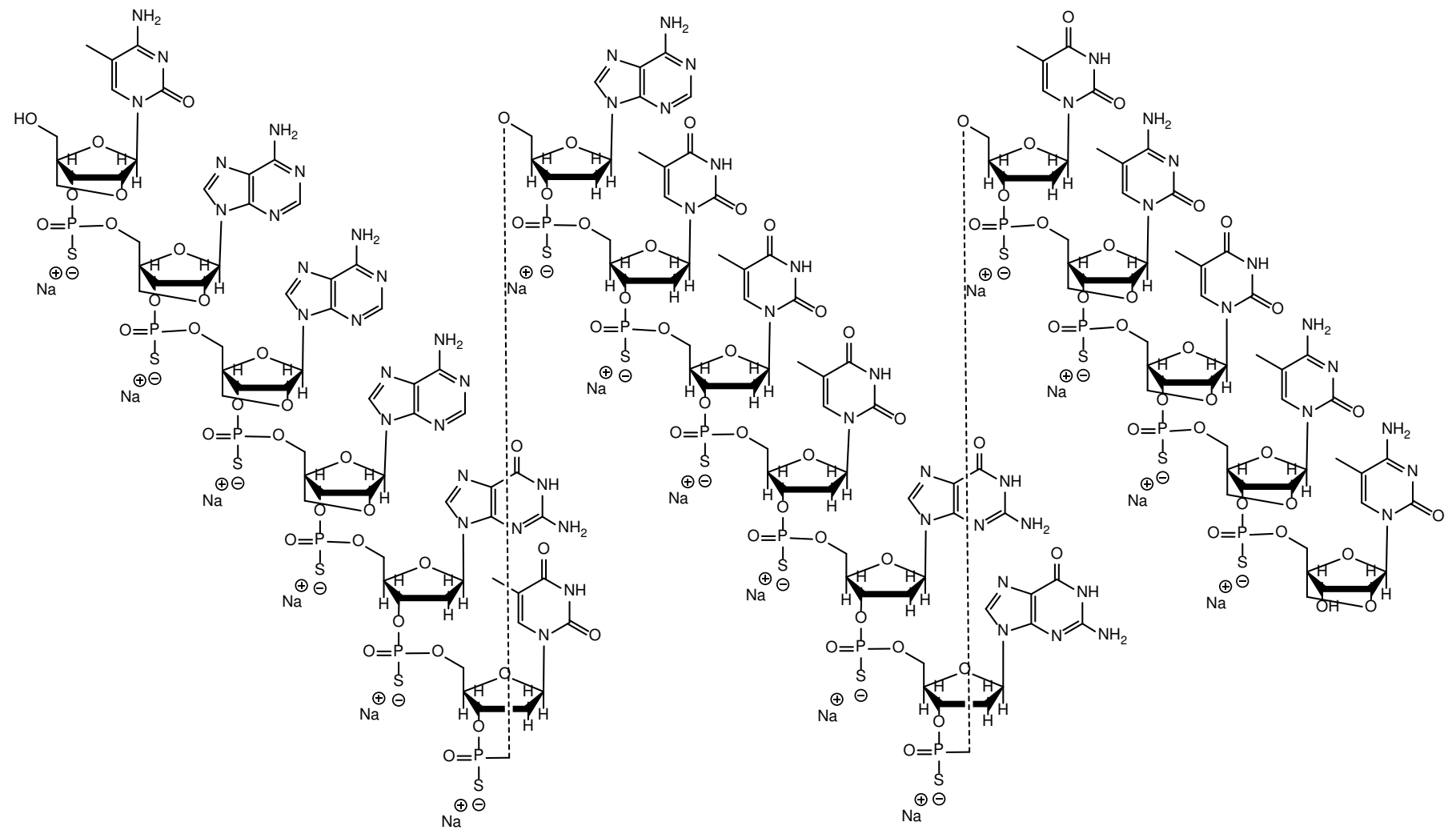


Supplementary Figure 2

\section{A ISTH1047: 5'TCGATGCGCTTCCG-3'}

Homo sapiens transforming growth factor beta 1 (TGFB1), mRNA

Sequence ID: NM 000660.6 Length: 2741 Number of Matches: 1

Range 1: 966 to 979 GenBank Graphics

\begin{tabular}{lllll}
\hline Score & Expect & Identities & Gaps & Strand \\
28.2 bits $(14)$ & 24 & $14 / 14(100 \%)$ & $0 / 14(0 \%)$ & Plus/Minus \\
\hline
\end{tabular}

Query 1 TCGATGCGCTTCCG 14

sbjet 979 TCGATGCGCTICCG 966

Mus musculus transforming growth factor, beta 1 (Tgfb1), mRNA

Sequence ID: NM 011577.2 Length: 2191 Number of Matches: 1

Range 1: 994 to 1007 GenBank Graphics

\begin{tabular}{lllll}
\hline Score & Expect & Identities & Gaps & Strand \\
28.2 bits $(14)$ & 20 & $14 / 14(100 \%)$ & $0 / 14(0 \%)$ & Plus/Minus \\
\hline
\end{tabular}

Query 1 TCGATGCGCTTCCG 14

Sbjet 1007 TCGATGCGCTTCCG 994

\section{B ISTH0047: 5'CAAAGTATTTGGTCTCC-3'}

Homo sapiens transforming growth factor beta 2 (TGFB2), transcript variant 1, mRNA Sequence ID: NM 001135599.3 Length: 6016 Number of Matches: 1

Range 1: 3284 to 3300 GenBank Graphics

\begin{tabular}{llcl}
\hline $\begin{array}{l}\text { Score } \\
34.2 \text { bits(17) }\end{array}$ & Expect & Identitie \\
\hline Query 1 & 0.39 & $17 / 17(100$ \\
Sbjct 3300 & CAAAGTATTTGGTCTCC & 17 \\
& CAAAGTATTTGGTCTCC & 3284
\end{tabular}

Mus musculus transforming growth factor, beta 2 (Tgfb2), mRNA

Sequence ID: NM 009367.3 Length: 4725 Number of Matches: 1

Range 1: 3029 to 3045 GenBank Graphics

\begin{tabular}{lllll}
\hline Score & Expect & Identities & Gaps & Strand \\
34.2 bits $(17)$ & 0.32 & $17 / 17(100 \%)$ & $0 / 17(0 \%)$ & Plus/Minus \\
\hline
\end{tabular}

Next Match A Previous Match

Strand

Plus/Minus

\section{Query 1 \\ Sbjet 3045 \\ CAAAGTATTTGGTCTCC


A

LN-308
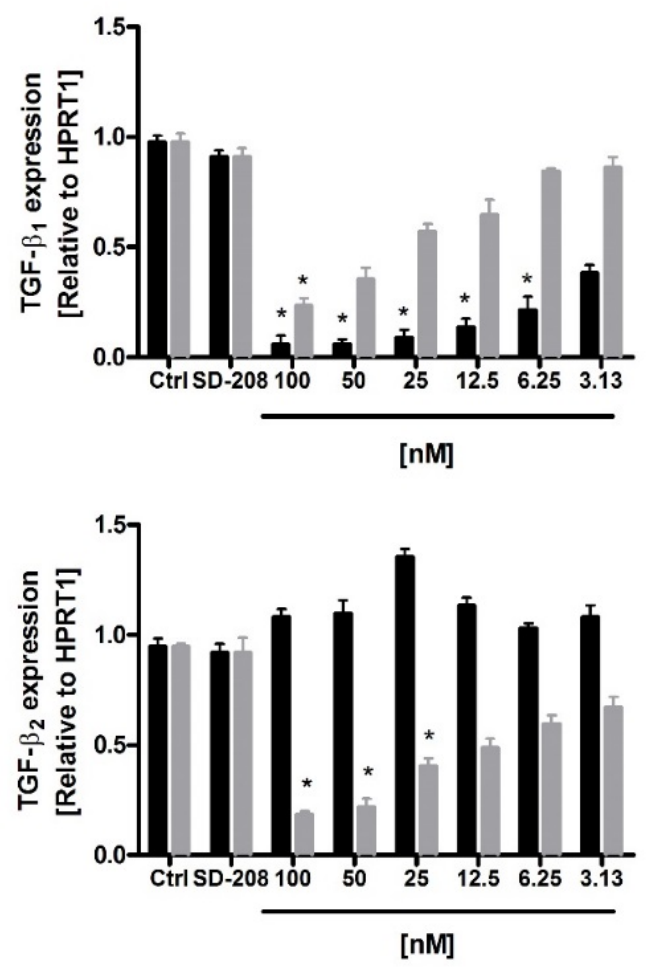

C LN-308

\begin{tabular}{|lllllll} 
& \multicolumn{5}{c}{ ISTH1047[nM] } \\
\cline { 2 - 7 } Ctrl SD-208 & 100 & 50 & 25 & 12.5 & 6.25 & 3.13 \\
\hline & & & & & \\
\hline
\end{tabular}

PSMAD2

total SMAD2

$\beta$-actin

ISTH0047 [nM]

Ctrl SD-208 $\begin{array}{lllllll}100 & 50 & 25 & 12.5 & 6.25 & 3.13\end{array}$

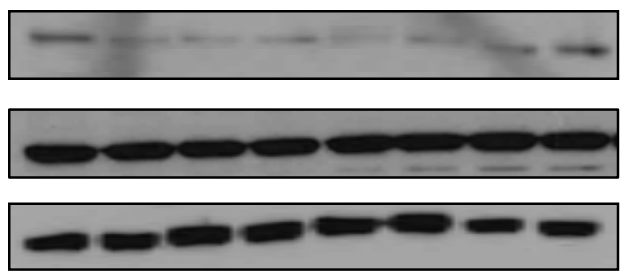

PSMAD2

total SMAD2

$\beta$-actin
B
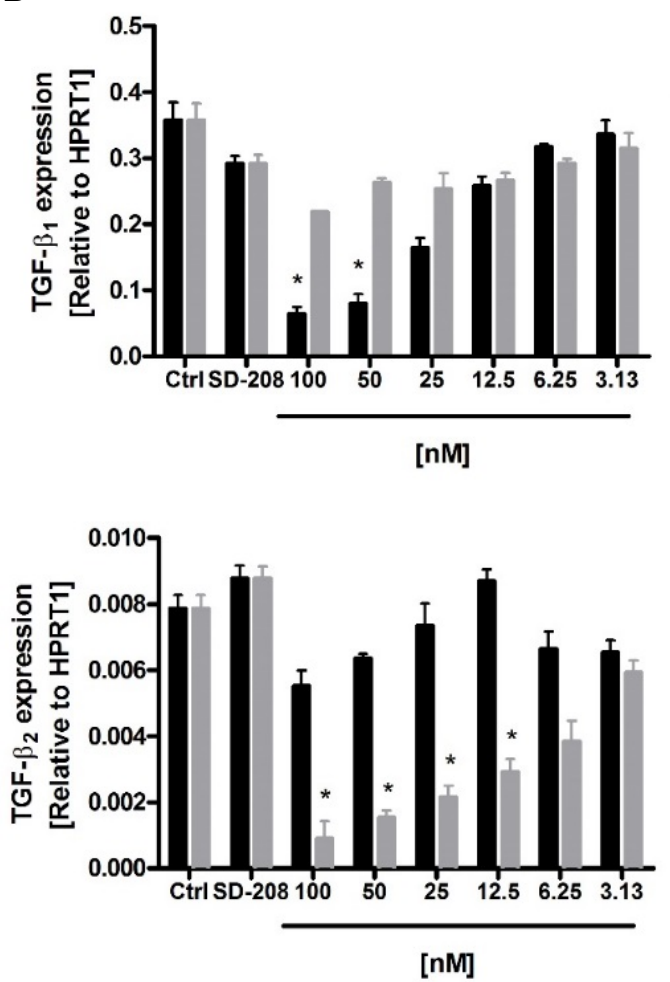

D

SMA-560

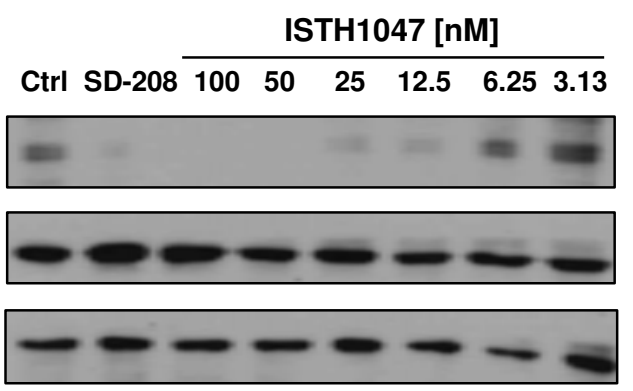

PSMAD2

total SMAD2

$\beta$-actin

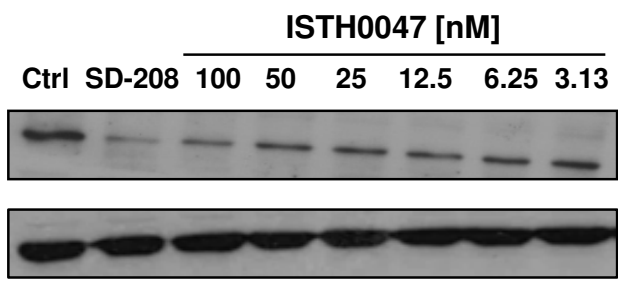

PSMAD2

total SMAD2

$\beta$-actin 

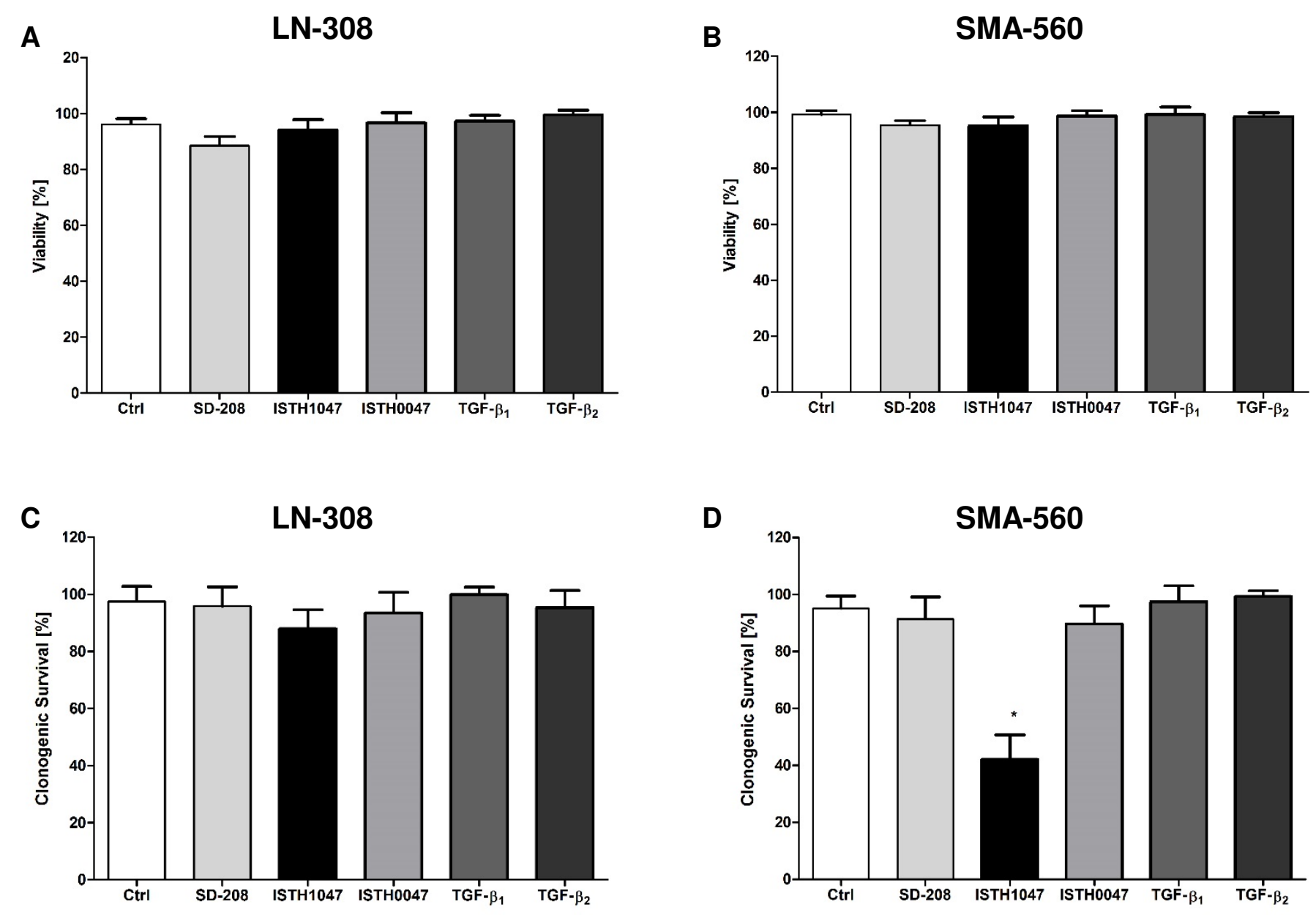


\section{Supplementary Figure 5}

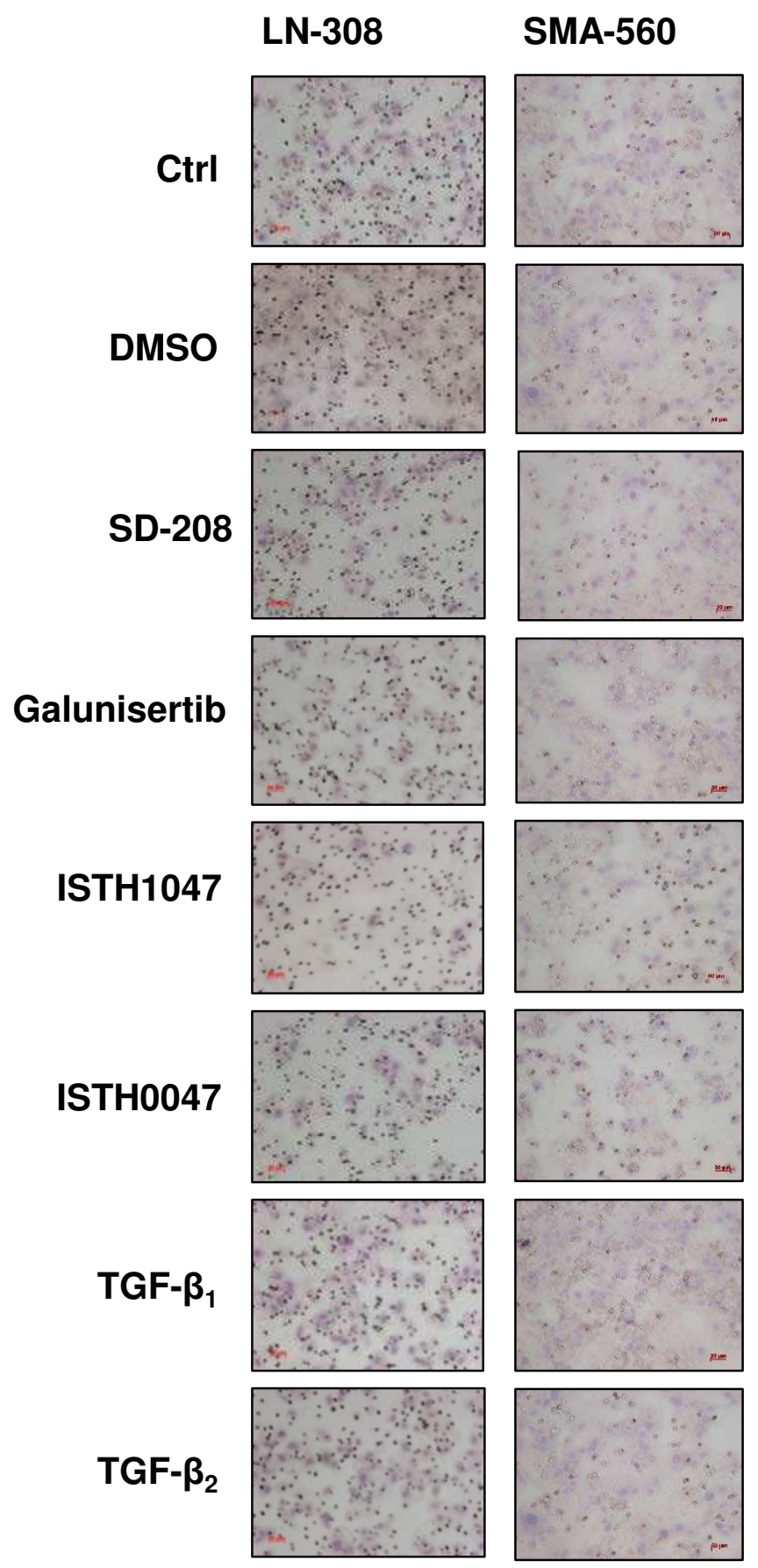

Galunisertib 
Supplementary Figure 7

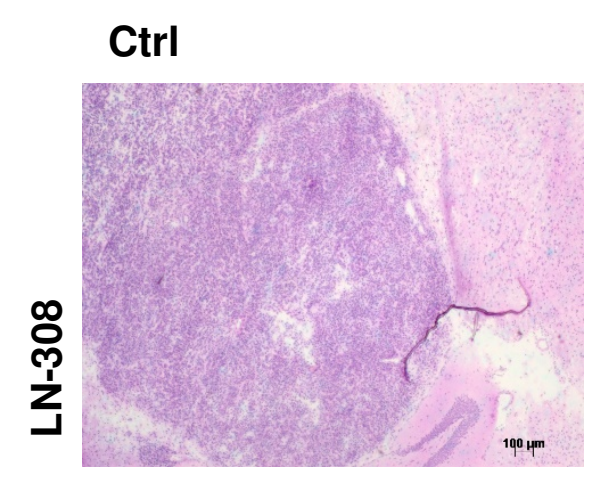

ISTH1047
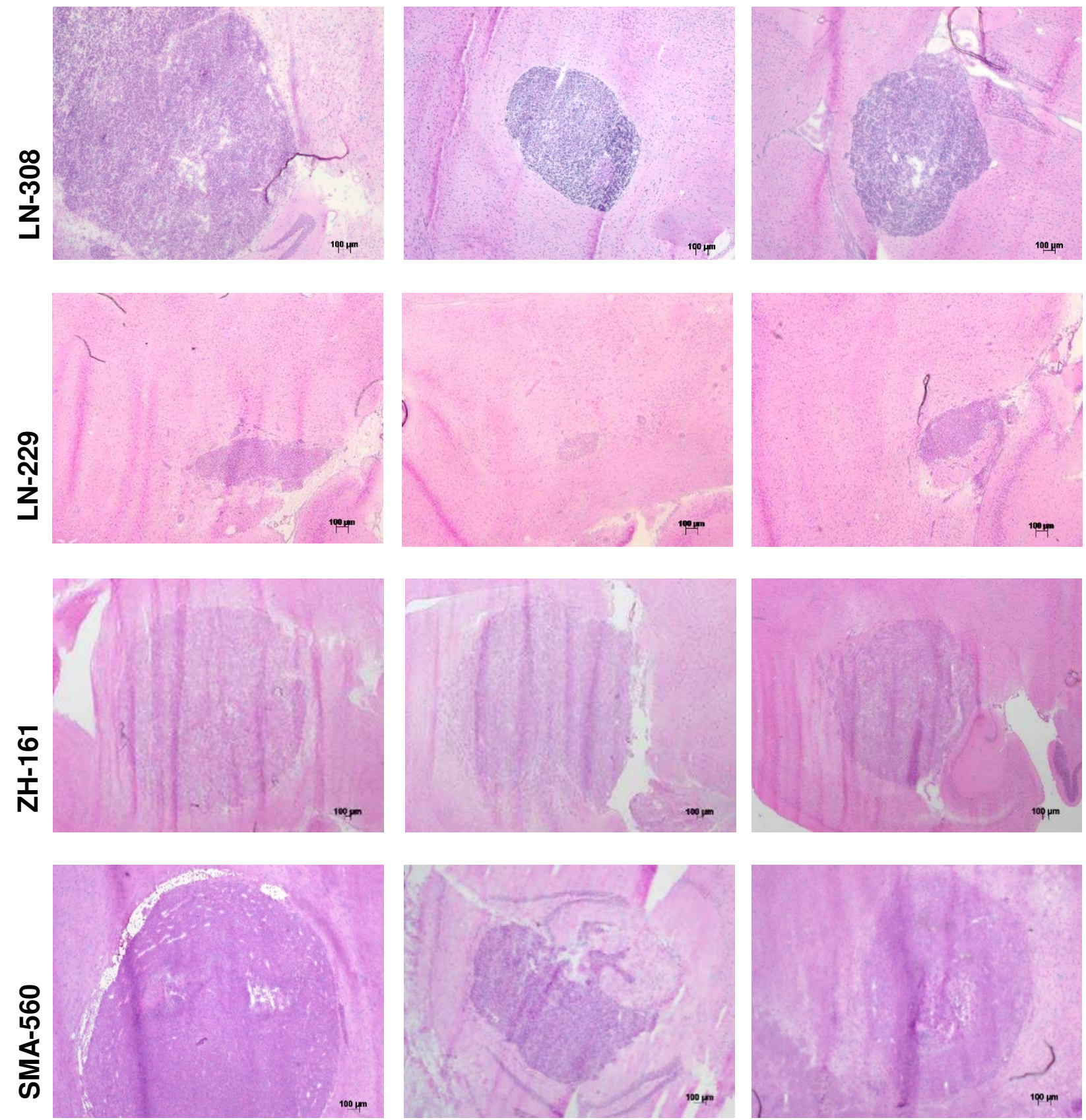

ISTH0047
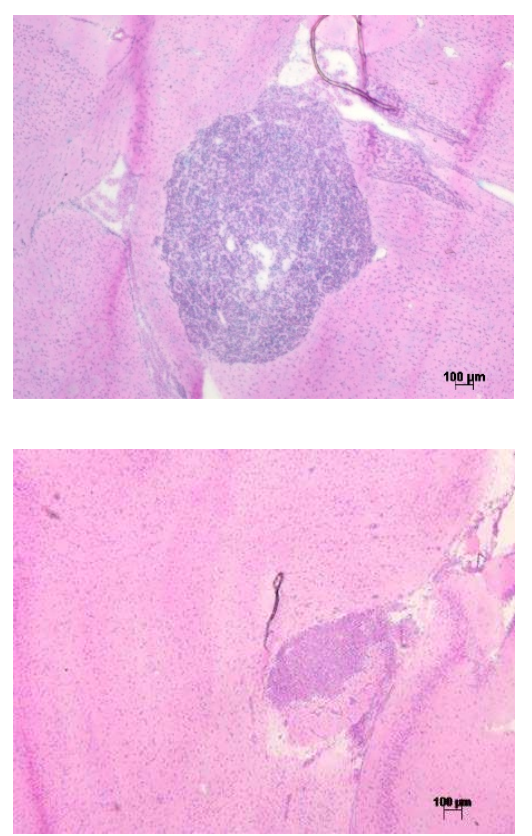

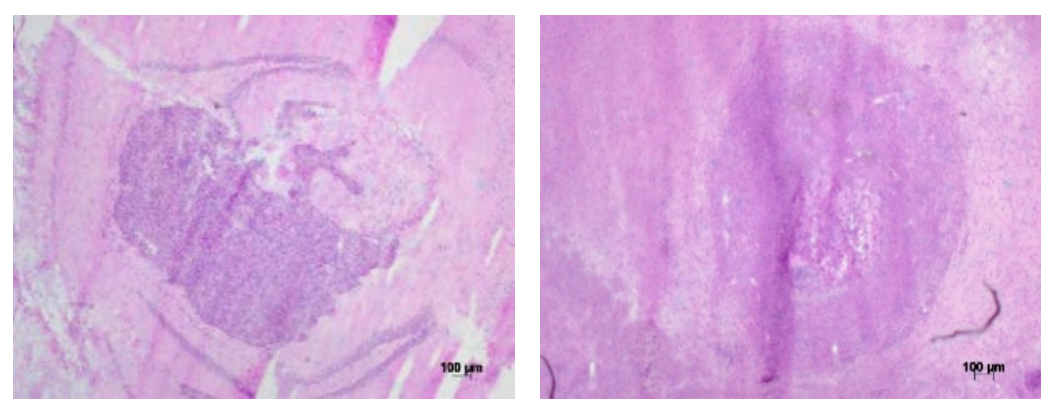


A

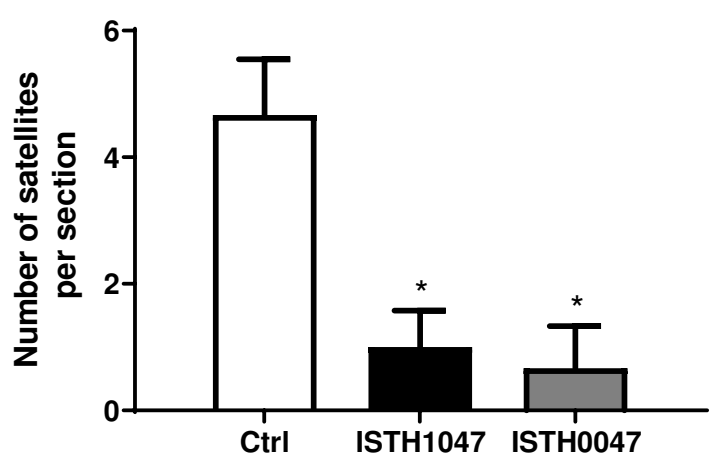

C

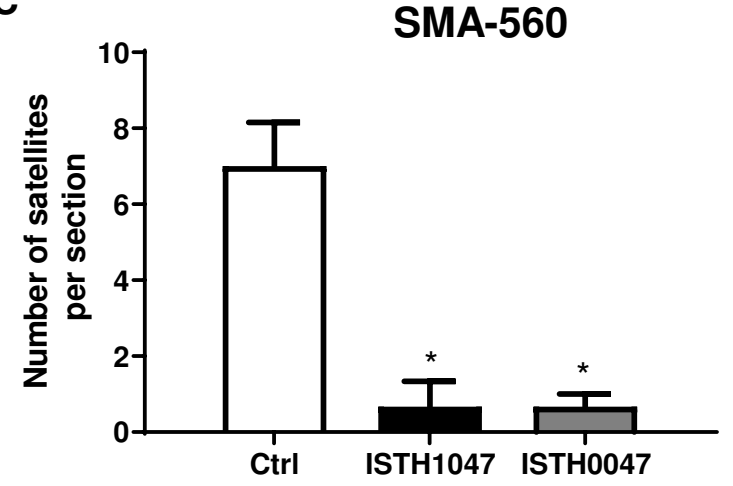

B

LN-229

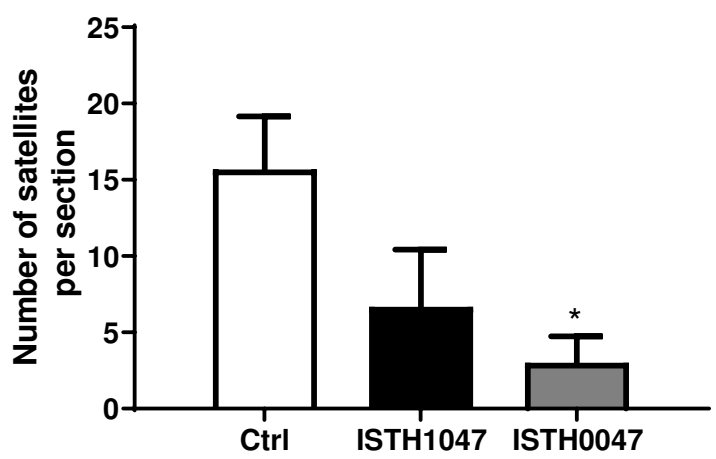

D Ctrl

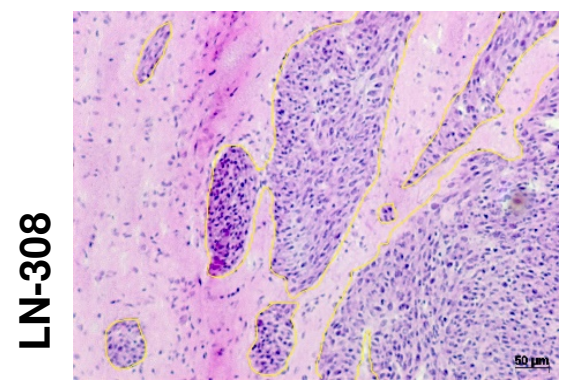

$\underset{\text { Nิ }}{\stackrel{2}{Z}}$

.

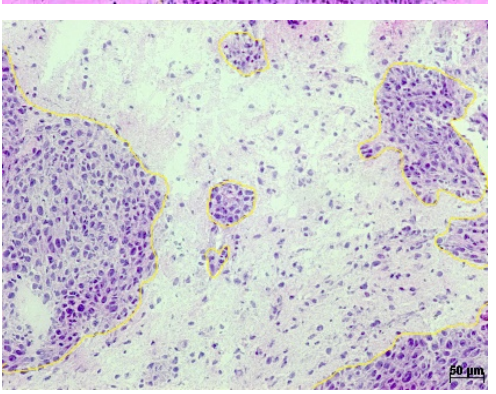

ISTH1047
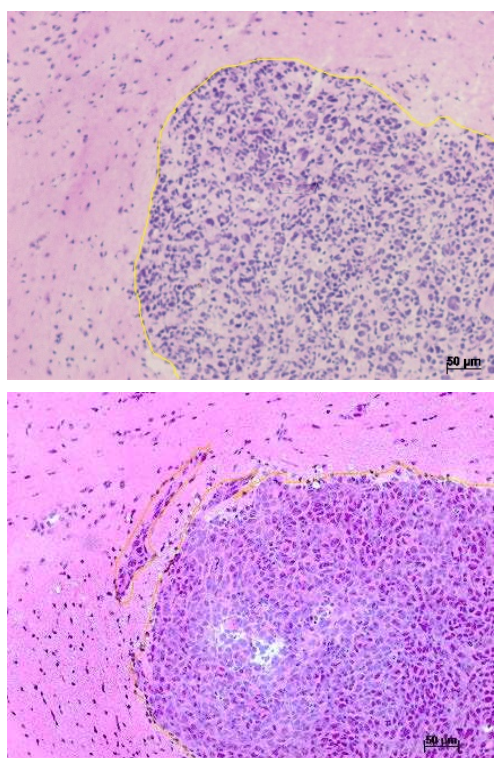

ISTH0047

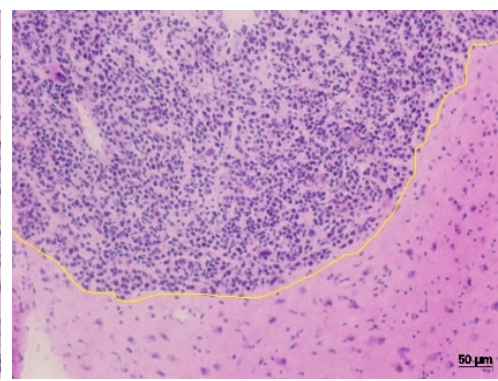

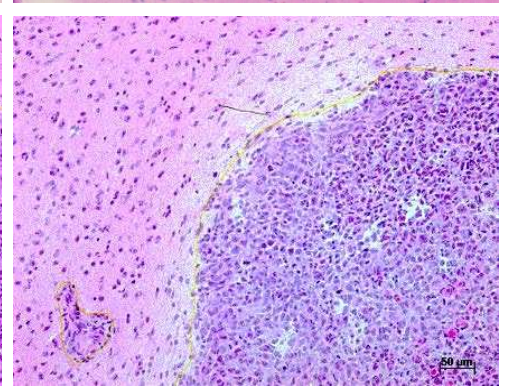
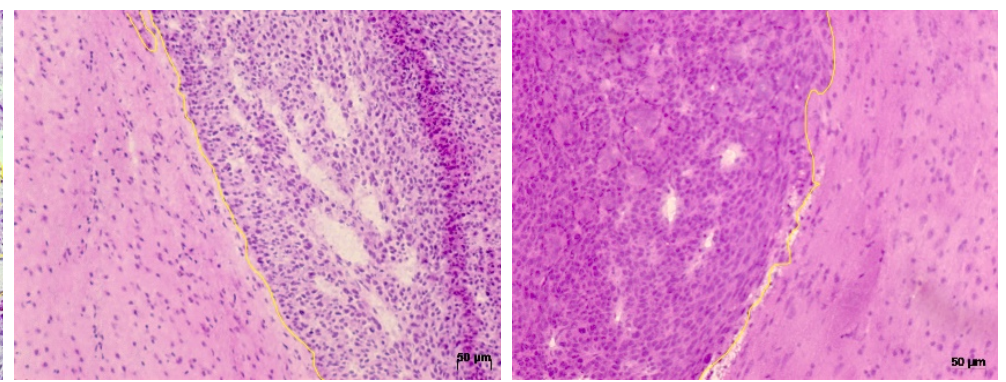
Supplementary Figure 9

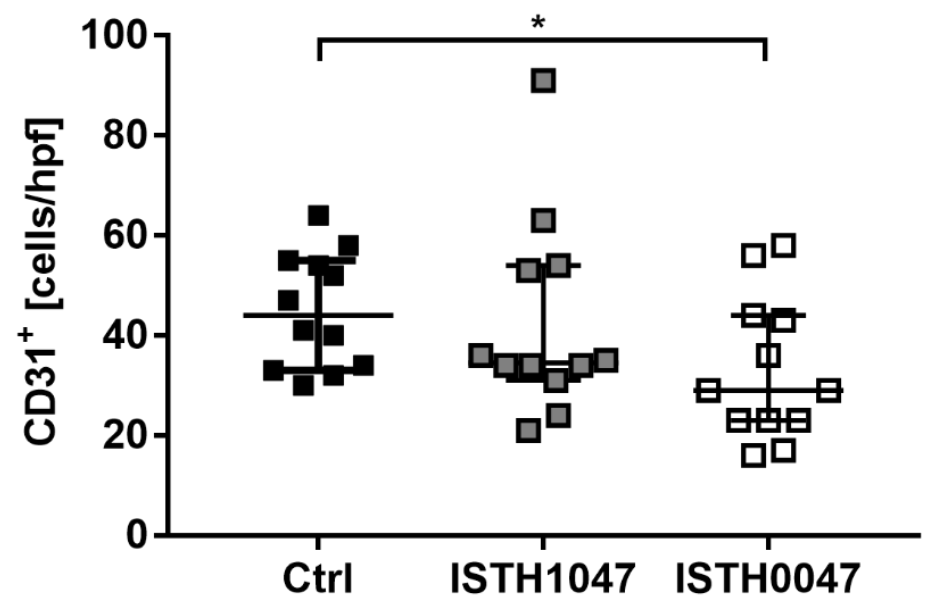


A

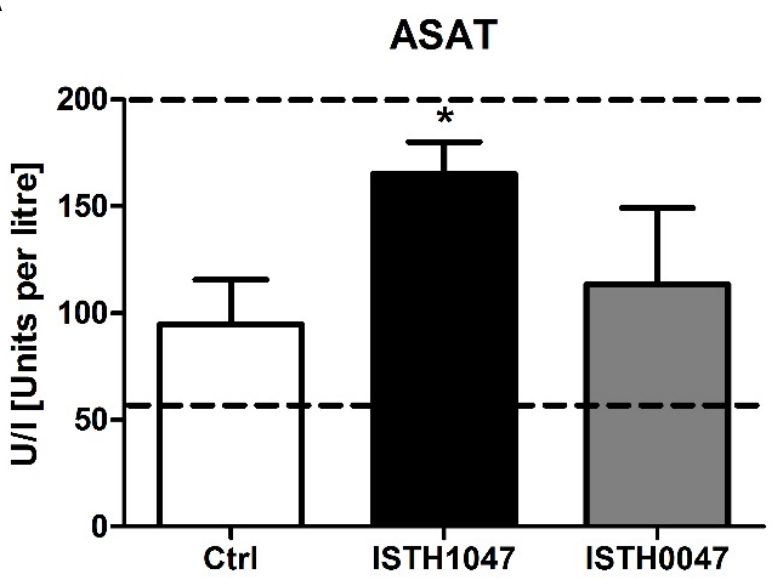

B

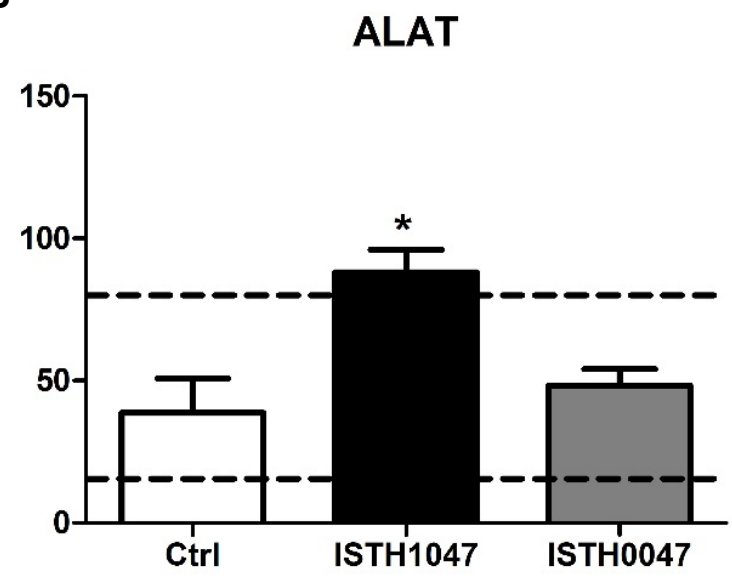

